\title{
The Cost Efficiency and Communication Effects Associated with Brand Name Exposure within Motion Pictures
}

\author{
Eva Marie Steortz \\ West Virginia University
}

Follow this and additional works at: https://researchrepository.wvu.edu/etd

Part of the Journalism Studies Commons

\section{Recommended Citation}

Steortz, Eva Marie, "The Cost Efficiency and Communication Effects Associated with Brand Name Exposure within Motion Pictures" (1987). Graduate Theses, Dissertations, and Problem Reports. 8214. https://researchrepository.wvu.edu/etd/8214

This Thesis is protected by copyright and/or related rights. It has been brought to you by the The Research Repository @ WVU with permission from the rights-holder(s). You are free to use this Thesis in any way that is permitted by the copyright and related rights legislation that applies to your use. For other uses you must obtain permission from the rights-holder(s) directly, unless additional rights are indicated by a Creative Commons license in the record and/ or on the work itself. This Thesis has been accepted for inclusion in WVU Graduate Theses, Dissertations, and Problem Reports collection by an authorized administrator of The Research Repository @ WVU. For more information, please contact researchrepository@mail.wvu.edu. 
THE COST EFFICIENCY AND COMMUNICATION EFFECTS

ASSOCIATED WITH BRAND NAME EXPOSURE WITHIN MOTION PICTURES

\section{THESIS}

Submitted to the Perley Isaac Reed School of Journalism

$$
\text { of }
$$

\section{West Virginia University}

In Partial Fulfillment of the Requirement for

The Degree of Master of Science in Journalism by

Eva Marie Steortz

Morgantown

West Virginia 


$$
\begin{aligned}
& \text { W } \\
& 398.7543 \\
& \text { Joust. } \\
& \text { st } 420 \\
& \text { c. } 3
\end{aligned}
$$

Libraxy Weat Virgindis Uni reesthy 


\section{ACKNOWLEDGMENTS}

During my research adventure, I joked that my acknowledgment section would be the largest in my thesis. Ultimately, it is the largest with regards to importance. This project was completed with the support, encouragement and help of many to whom I extend heart-felt gratitude.

Sincere thanks to my committee members, Dr. John Boyer, (Chairperson), Dean Guy Stewart, Dr. Robert Cook, Professor Bob Summers, and Professor Charles McCann, for their pats on the back as well as their kicks in the butt.

Computer analysis of the data would have never transpired without the patient assistance of Kathy Fletcher, WVU Computer Consultant.

My sincere thanks are also extended to S. Michael Camp, president of IMPAC, a marketing research firm. From the beginning Mike gave practical direction to a flurry of 1deas. He was also very instrumental in the execution of the SAS computer programs-- he did them.

To my friends at Institutional Advancement, WVU, where I was employed during the duration of my graduate studies-- thanks for understanding my dedication to completing my masters and allowing me to have such a flexible schedule. A special thanks to Tim Truman who may have worried more than me about the typing and format of this thesis.

Thank you also to those professionals listed in the Appendix who took the time to respond to my requests for information and suggestions. Their

interest and encouragement were major reinforcers.

A lot of credit must be extended to my friends who kept me sane. I thank them for unconditionally standing beside me while my moods swung from frustration to elation.

And last, but not least, I dedicate this thesis to Mom and Daddy for their continuous faith and money when I had none. Any success I encounter is because of them and for them. 


\section{TABLE OF CONTENTS}

Acknowledgments.........................................1

List of Tables and Illustrations.............................11

Introduction $\ldots \ldots \ldots \ldots \ldots \ldots \ldots \ldots \ldots \ldots \ldots \ldots \ldots \ldots \ldots \ldots \ldots \ldots \ldots \ldots \ldots \ldots \ldots \ldots \ldots \ldots \ldots \ldots \ldots \ldots 1$

Review of Literature......................................9

Justification $\ldots \ldots \ldots \ldots \ldots \ldots \ldots \ldots \ldots \ldots \ldots \ldots \ldots \ldots \ldots \ldots \ldots \ldots \ldots \ldots \ldots \ldots \ldots \ldots \ldots \ldots \ldots \ldots \ldots \ldots \ldots 12$

Purpose of Study $\ldots \ldots \ldots \ldots \ldots \ldots \ldots \ldots \ldots \ldots \ldots \ldots \ldots \ldots \ldots \ldots \ldots \ldots \ldots \ldots \ldots \ldots \ldots \ldots \ldots \ldots \ldots$

Limitations..............................................18

Definition of Terms..........................................22

Methodology...............................................24

Results...................................................34

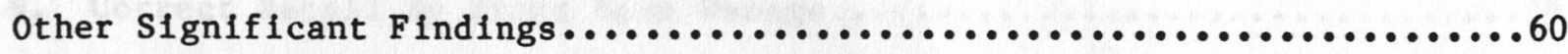

Suggestions for Further Research..............................63

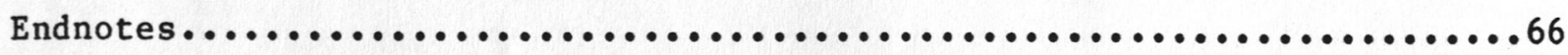

Sources Cited...............................................68

Appendix.1/ Summary of Data Per Movie...........................70

Appendix 2/ List of Professionals Interviewed....................76

Appendix 3/ Sample Questionnaires.............................. 77

Appendix $4 /$ Sample Correspondence................................ 83

Abstract $\ldots \ldots \ldots \ldots \ldots \ldots \ldots \ldots \ldots \ldots \ldots \ldots \ldots \ldots \ldots \ldots \ldots \ldots \ldots \ldots \ldots \ldots \ldots \ldots \ldots \ldots \ldots \ldots \ldots \ldots \ldots \ldots$

Resume..................................................86 


\section{LIST OF TABLES AND ILLOSTRATIONS}

\section{Title}

1. Placement Descriptions....................................32

2. Sample Description/Age By Sex............................. 38

3. Placement By Recall Effectiveness...........................47

4. Placement Types By Average Recall.............................48

Illustration 1 Confidence Intervals..... ..................... 51

5. Sex By $\operatorname{Recal1} \ldots \ldots \ldots \ldots \ldots \ldots \ldots \ldots \ldots \ldots \ldots \ldots \ldots \ldots \ldots \ldots \ldots \ldots \ldots \ldots \ldots \ldots \ldots \ldots \ldots \ldots \ldots . . \ldots 2$

6. Correct Recall/Sex By Placement Type..........................52

7. Correct Recall By Age...................................55

8. Seconds Brand Name Exposure By Average Recall ...................57

9. Correct Recall By Brand Name Useage.......................... 58

10. Correct Recall By Rate...................................62 


\section{HOLLYWOOD'S NEW SILENT FILM STARS:}

\section{BRAND NAME PRODUCTS IN MOTION PICTURES}

Bette Midler and Shelly Long crossed the country and went to hysterical lengths in Outrageous Fortune to track down a man who had been two-timing them. When they finally found him, it was a critical moment for them and for the film. Before they entered the boathouse where their lover was hiding, lipsticks and compacts were exchanged and shelly was sport enough to offer Bette a Tic Tac.

In Nightmare on Elm Street III, a young girl haunted by Freddie, the famous disfigured dream murderer, eats a spoonful of Maxwell House Coffee and washes it down with Diet Coke to stay awake.

The lovable monkeys who were trained to fly Navy fighter jets in Project $X$ were given Sun Maid raisins and Twinkees for rewards.

Brand name products have been making appearances on the silver screen since the beginning of the cinema. Jack Daniels bourbon made its film debut when Joan Crawford served it in the 1945 movie, Mildred Pierce. ${ }^{1}$ However, only recently has such a great effort been exerted by those involved in this "advertising" technique. Many credit this growing trend to E.T., Steven Spielberg's lovable little alien creature, who followed a trail of Reese's Pieces to a documented 65 percent increase in sales for the Hershey company in 1982 . 
Interestingly, there is no research available concerning the communication effects associated with a brand name's exposure within a motion picture. The E.T. story is often cited along with the popularity of Ray Ban sunglasses following Tom Cruise's Risky Business, but these obviously are not representative samples of the results of what has become known as product placement.

An encompassing definition of product placement is the featuring of brand identified merchandise within the body of a feature film.

Product placements are essentially business deals with potential advantages and disadvantages for all involved. First, who is involved? There are the manufacturers who seek exposure for their brand name products and merchandise. Escalating television advertising rates, a decline in network viewing and other concerns have resulted in brand managers and marketing directors looking for alternative ways of gaining consumer awareness.

The motion picture studio people are interested in gaining realistic props, but they are also facing limited budgets and limited time frames. Product placement is often a solution since the product placement firm warehouses provide one-stop shopping so that an entire movie set may be furnished with props.

Jeff Coleman of Paramount Pictures emphasized the creative concerns of the motion picture studio when it comes to product placement. He said the entertainment aspect of 
the movie must come first. Coleman cites an example from Star Trek IV in which a billboard for Pacific Bell became the source of a joke within the movie. ${ }^{3}$

Product placement gets complex when one tries to describe how these business arrangements transpire because at this time there are no standard contracts, standard fees and essentially no standard rules. Robert Blanchard, Vice President of Marketing at Colgate-Palmolive, compared product placement to a "Turkish rug market." 4

The prosperity of product placement firms depends on close relationships with movie studios. These relationships enable them to get many movie scripts far in advance of production. The closer the relationship, the more scripts acquired and the more exclusive opportunities they can maintain. A representative from Unique Product Placement, one of the largest placement firms, indicates that contacts at the blue collar level are also pertinent in gaining product inclusion in motion pictures.

Product placement firm representatives break down scripts and identify scenes where a client's product could be incorporated. They, of course, also look for additional opportunities that would enable them to gain new clients. Supposedly the manufacturer makes the final decision regarding the movies in which their brand names appear. Alice Gereaux, Sales Promotion Coordinator at Anheuser-Busch, expresses the importance of the quality of their placements versus the quantity: 
Some scripts simply are not acceptable. This can be due to poor quality, unfair or improper use of our products, improper target audience for beer brand exposure, and/or an array of other factors. 5

Melvin S. Grayson of Nabisco Brands Incorporated says their company-wide proviso is that any movie in which their product is displayed must have a G-Rating. ${ }^{6}$ However, there are no rules that prohibit a propman from dressing a set with what ever product is accessible. Obviously, it is in the studio's best interest to secure permission before using a brand name so as not to jeopardize future relationships with manufacturers.

The manufacturers who hire agencies to handle their product placement promotions now have between thirty and forty firms to choose from; most are based in the Los Angeles area, but a few are located in New York City. Manufacturers who decide to invest in Unique Product Placement's services, pay annual fees which range from $\$ 25,000$ to $\$ 500,000$. The fee is based on agreements which are outlined in a contract. Manufacturers are guaranteed a certain number of "acceptable" placements within a certain time period. Acceptable placements are defined by product placement firms as "clearly visible to the audience." 7 In other words, a product may appear on a shelf in the background of a scene.

Clients of Diener/Hauser/Bates Co., Inc., are given a minimum fee and a ceiling level for the cost of each placement. Manufacturers must give the firm a retainer sum of $\$ 100,000$. For each placement, a charge of $\$ 1,000$ for every one million national box office attendance (as published in the Hollywood Reporter) is 
subtracted from the retainer. The firm keeps $\$ 25,000$ at the end of the year for operating expenses even if no exposure is received. 8 Many firms also offer additional services to help manufacturers capitalize on their product placements. Some work with manufacturers to develop promotional tie-ins at the retail level. They may develop point-of-purchase displays or back-end promotions. Contests and sweepstakes are also becoming popular. Miller Genuine Draft, Norm Marshall and Associates and Universal combined efforts for the Dragnet movie sweepstakes contest. Details are found on point-of-purchase displays at retail outlets and Dragnet badge identification numbers for the contest were printed on the beer labels. Prizes are Dragnet props such as a 1987 Corvette and the Dragnet Police Cruiser. Doug Christoph, Director of Young Adult Promotions at Miller explains:

It was a 7 million dollar tie-in. This was our first such national consumer promotion. Our sales staff and distributors were motivated...it was our largest volume month for Miller Genuine Draft. ${ }^{9}$

Manufacturers who use placement brokers supply a stock of the products and other promotional merchandise to be stored in a warehouse. Associated Film Promotions has a 12,000 square foot warehouse filled with over 800 items ranging from computers to baking soda. 10

The product broker, having recognized an opportunity for placing a client's product, will call upon the property master and offer the merchandise free of charge. In most cases, there are 
guarantees that the merchandise will be returned when filming is complete.

Property masters also visit the warehouse to find realistic props to dress their sets. This is an especially attractive arrangement when the movie requires expensive props such as computers, stereos or heavy equipment. Prior to this type of arrangement, rental fees were paid by the studio.11

Bartering is also used in product placement business arrangements. Hotels and airlines may offer free accommodations for cast and crew in exchange for exposure. Many car manufacturers have someone on staff whose sole responsibility is establishing good public relations with movie and television studios.

They offer use of their cars to cast and crew in exchange for scenes in which actors drive their automobiles. "The bidding - doesn't involve money, but rather how many onscreen placements you expect in return for lending cars to the offscreen crew," said Frank Devaney of Rogers \& Cowan, Los Angeles, representing the Ford Motor Co. 12

It is not uncommon for food, soft drink and beer manufacturers to send cases of their products to movie studios to establish favorable relationships and hopefully get some exposure. ${ }^{13}$ Movie studios are now recognizing their opportunity to capitalize on these business arrangements. If a movie has popular actors or is being directed by someone who has a history of successes, fees may be charged for exposure and used to underwrite production and promotion costs. 
New Line Cinema's Michael Harpster indicates their studio is getting more involved with product placement. "When we see an opportunity, we approach manufacturers and see if they are interested in making a deal."14

Curiously, some well-integrated placements and blatant endorsements are "freebies." Sometimes brand names appear on the screen because a prop man or an actor either has the product or runs out and arbitrarily chooses a brand name. Interestingly, the placement within this study which received the highest brand name recall, 93 percent, was a "freebie."

"We were contacted because the script called for extensive use of diapers," said George Ker, Vice President of Advertising at Kimberly-Clark Corporation which manufacturers Huggies. "We agreed as long as our brand name was used in a positive way."15

Huggies diapers did appear extensively in Raising Arizona. Huggies was the only brand shown in nursery scenes. Huggies was mentioned in the dialogue. The star of the movie chose Huggies from a store shelve and then dropped them from a speeding car and then retrieved them from the same speeding car. Throughout each scene the Huggies package was highlighted. Kimberly-Clark has paid for placements within movies in the past. "Some times you just get lucky," concluded Ker.

Unfortunately, practitioners who were interviewed expressed knowledge of some unscrupulous business arrangements among placement companies which "take the money and run." These companies promise placements to manufacturers and then fail to deliver any brand name exposure. Obviously, companies such as this are not in the 
business for long. However, since the industry is small bad news travels fast and the whole industry suffers. Thus, product placement does suffer from a lack of credibility.

An advertising agency representative who was interviewed, made reference to manufacturers' skepticisms concerning product placement. However, the number of Fortune 500 companies investing in product placement and the increasing use evident in recent movies, indicates manufacturers must have some degree of confidence in the ability of brand name exposure in motion pictures to influence consumers.

A great deal of competition already exists between product placement firms, between manufacturers and between movie studios. There is great potential for creative, financial and promotional advantages. However, the complexity of the business arrangements and ethical concerns have led the Promotion Marketing Association of America to establish a Film Promotion Council, the first such committee in the PMMAA's prestigious 80-year history. The goal is to finally set standards of performance and professionalism and to educate those involved to bring new credibility to the field. 16 Research such as conducted within this project will also enhance the reputation of product placement and establish its merit within a manufacturers' advertising strategy.

All indicators point to a continuing growth in the use of product placement. Further understanding of consumer reactions to brand name exposure within films is essential for any company which hopes to maximize product placement opportunity. 


\section{REVIEW OF LITERATURE}

Although there has been no credible academic research documented concerning product placement in motion pictures, articles have appeared in advertising and marketing trade periodicals over the past five years. A computerized literature search provides a historical perspective and a variety of opinions regarding the effectiveness of this type of mass communications.

For instance, Dennis Burnes, president of Gargoyles Sunglasses Company, divulged in ADWEEK:

In one 12-month period, Kovoloff (Associated Film Promotions president) was able to place our product on a star in three different movies, all were in the top five grossing movies of the year. We had people who literally walked out of the theatre and into the optical shop asking for our glasses...

John O'Toole, chairman of Foote, Cone \& Belding advertising agency in U.S. News and World Report said:

It's absolutely worthless. Flashing a package in front of somebody won't convince them to buy. Besides, the movie should come first, not ways to feature a product. 18

Ben Ennis, professor at the University of Southern California Business School, said:

When advertising is labeled as advertising it is filtered by customers. You process the information differently, but in the movie you can have the hero or heroine implicitly or even explicitly endorse the product. It's quite effective. 19

Some degree of skepticism must be applied to research results included in periodical literature. For instance, an Advertising Age article documented results from a study 
which Associated Film Promotion's had conducted:

Of the 1,600 people questioned about 'Rocky III' nearly 60 percent recalled Sylvester Stallone wolfing down General Mills' Wheaties, but only 1 percent remembered a quick shot of William Grant \& Sons' Glenfiddch scotch bottle. $20^{\circ}$

This researcher contacted Associated Film Promotions and requested information concerning the documented research results. There was no report available and no information disclosed concerning study methodology. For research results to be useful, one needs to know how samples were chosen, how questions were worded and what type of analysis was applied so that procedures can be analyzed and duplicated.

Literature is also available in the form of product placement firm sales kits. Since they are compiled to attract clients, information must be critically analyzed.

Unique Product Placement's sales kit states, "You can now reach millions of households more efficiently than print, radio or television advertising." 21 Estimated costs and audience sizes are documented with no attribution for figures. Comparisons are made to other media with no acknowledgement of inherent limitations.

Unique Product Placement's sales kit also suggests that "movies leave a lasting impression, with documented proof of recall at the time of purchase." The company's "documented proof" were articles written by Nora Rotkin, a behavioral scientist at Stanford University. Further probing revealed 
that Nora Rotkin had once been hired by Associated Film Promotions, a product placement firm competitor, to provide justifying research for the benefits of brand name exposure within motion pictures. Her articles include concepts such as "unconscious impression," and "subliminal perceptions." This researcher found a two page article written by Dr. Rotkin in an issue of Marketing Communications. This article contains a response card for Associated Film Promotions and is labeled as an advertisement. 22

Articles published in the Journal of Marketing Research, Journal of Advertising, Journal of Advertising Research and books published on advertising and mass communications research are used to review procedures utilized in the past to determine communication effectiveness. Comparisons are made between this project's results and documented results from other advertising effectiveness studies.

Reference materials such as Simmons Market Research Reports and Variety are used for compiled audience sizes which are used for comparisons within the present study. 


\section{JUSTIFICATION}

The need to reach a highly segmented population and increasing television, radio, magazine and newspaper advertising rates have resulted in manufacturers seeking alternative vehicles for gaining brand name exposure. ${ }^{23}$ Advertising within motion pictures is now an option for manufacturers. However, there is no reliable or valid research concerning the communication effects or cost efficiency associated with a brand name's appearance in a motion picture.

In fact, the main problem facing manufacturers at this time is the lack of resource materials concerning the use of product placement in motion pictures as a tool for gaining effective, memorable brand name exposure.

Available quantified data take the form of estimated total audience sizes based on theatre attendance, VCR tape rental and cable television viewing of past motion pictures. These numbers are adequate if manufacturers want reinforcement that their brand name is being exposed within a medium with a large vehicle audience size. Problems arise when one considers vehicle size does not indicate how many watching the movie actually saw the featured brand name. of what value is exposure if the trademark or product package did not register within the consumer's mind?

This study applies scientific techniques to generate valid and reliable brand name recall frequencies that can be 
used to predict the communication effectiveness associated with product placement.

This assemblage of objective and pertinent information provides a reference guide for manufacturers. This study also provides a great deal of insight, examples and data which can be used when deciding if product placement in motion pictures would be an effective and cost efficient addition to an overall advertising strategy.

The importance of research is unfortunately recognized by only a few practitioners. This is represented by the absence of data available concerning product placement even though many manufacturers are investing substantial chunks of their promotional budget on this advertising technique.

Product placement and other more creative means of gaining brand name exposure are important in a time when consumers are learning to filter out many of the advertising messages with which they are bombarded. Leo Bogart reflects my justification for this project when he wrote:

Advertisers ought to assign a higher percentage of their budgets to research that helps them create successful ads. 24

Only through research will product placement be fully utilized. 


\section{PURPOSE OF THE STUDY}

This study provides a history, background and an objective, systematic exploration of the communication effects associated with a brand name product's appearance in a motion picture. A multiplicity of sources was utilized to ensure a complete analysis of the topic. A secondary literature review, interviews with experienced professionals and a survey of movie-goers was conducted.

This study's primary purpose is to offer manufacturers and their advertising agencies useful information and informed insight to consider prior to an investment in product placement. Possible advantages and disadvantages of product placement are analyzed and compared to the documented results of advertising on television. Comparisons are also made to "sponsored trailers" which are essentially 60 - and 90- second commercials that are being shown before the feature movie in a theatre. The limitations of these comparisons will be fully outlined.

Perhaps the most important contribution of this project is the generation of quantified recall levels for a variety of product placements in current movies. It seems imperative that a movie-viewer be aware of a product's appearance in a motion picture for the placement to be of any promotional value to a manufacturer. Therefore, communication effectiveness will be measured by frequency of brand name recall to empirically justify product placement 
investment. This researcher finds recall a more accurate measure of effectiveness than vehicle audience size. Projected audience size is the potential number of people who may be influenced by a message. Many media budget allocations continue to be based on audience size even though this technique has been criticized by practitioners and academia for decades. In 1962, Wolfe et al. said in their widely circulated Conference Board review:

Mere counts of people exposed are not in themselves adequate measures of how effective advertisements have been... a better evaluation is possible by picking up the thread at a later stage in the communication

lipon investing in product placement, manufacturers of ten do not even know in wich movies their products will appear. Since manufacturers usually can be given no guarantee as to how their products will be incorporated into a movie, this study will generate recall levels for different types of product placements.

It is important to note that under some circumstances a manufacturer can pay movie studios extra fees in exchange for guarantees their product will be used in a prominent way. This again warrants the need for empirical data concerning the implications of the different ways a manufacturer's brand name may appear within a motion picture. Are there significant differences in brand name recall?

The generation of recall scores for five various types of placements also will allow manufacturers to categorize each of 
their placements and better predict the impact of their brand names' exposure on the estimated audience size.

The time (in seconds) the brand name appeared on the screen also was cross-tabulated with average brand name recall scores. Evidence that various types of placements and various time lengths do result in different degrees of effectiveness may justify a product placement cost structure. At this time, fees seem to be based on a variety of variables. Sometimes "guesstimates" of total audience size throughout the life of the film are used for developing fees. Within other product p]acement firms, payment is subjectively based on the effort exerted for each client.

This study offers informed insight by attempting to establish additional variables that impact the memorability of a product placement. The relationships between recall and repeat viewing, brand usage and rating of the movie are also analyzed through cross-tabulation and chi-square tests.

Demographic age segments and sex are also variables analyzed by cross-tabulation.

Data generated from such analysis indicates the impact which can be expected when various variables are inherent within a product placement.

The present study also indicates differences in memorability among various demographic segments so that practitioners may better utilize product placements targeted to specific audience members. 
Thus, the information generated can be useful in developing effective product placements as well as evaluating the performance of product placements as they occur. 


\section{LIMITATIONS}

Research involving the communications effects of mass media is by its nature subject to limitations. Lowery and Defleur write in Milestones in Mass Communication Research:

The function of media portrayals are most likely subtle, long range, accumulative and nearly impossible to sort out from other kinds of communication processes. 26

This signifies the difficulty in designing a study to explore exclusively the effects of one medium. Therefore, when analyzing audience perceptions and recall levels of product placement it is necessary to acknowledge the influence of information stored from other media and opinions from peers.

It should also be noted that the validity of recall tests to measure advertising effectiveness is subject to controversy. In 1972 , Herbert krugman reported that recall understates the true remembrance of advertising. He explains that techniques requiring verbalization favor thinking or left brain advertising as opposed to affective or feeling advertising. 27

Another basis for the criticism concerning recall tests is the lack of data relating recall to purchase. $28 \& 28$ ur assumption, however, is that no manufacturer really believes that any one isolated advertising effort affects the sales of his merchandise. The unanimous feeling expressed among professionals interviewed was that the objective of getting products featured in motion pictures is brand name "exposure." 
A measure of exposure could simply be an estimate of how many people see a movie in which a product appears. However, this in no way is indicative of how many people noticed a product prop.

Therefore, recall testing is justified for measuring the performance of product placements. Recall scores indicate how many audience members saw and can remember a manufacturers' brand name appearing in a movie. Also, since recall testing is still the most commonly used indicator of advertising effectiveness, this technique is the most appropriate. The methodology undertaken ensured the documentation of results from other advertising effectiveness research which could be used for comparisons within this study.

This study will attempt to discover relationships between respondents' recall of product placements and variables hypothesized to be mediators of effectiveness. One variable tested is past product usage. This will be limited to the accuracy of the respondent's memory when noting product placement as well as his ability to categorize himself/herself accurately as a loyal, frequent, rare, trial or non-user of that brand product.

This thesis is also limited to the research of product placements within motion pictures. Brand name products are also appearing in music videos. There are network regulations, but some placements have been made within television shows. Research is required to explore the effects of these placements, but differing variables prohibit the effects to be studied in 
conjunction with motion picture placements. For instance, the audience views these placements in completely different environments and on different size screens. This research can only reliably be applied to motion pictures shown in theatres. The quantified recall levels cannot be generalized to VCR movies viewed in the home or movies viewed on cable television.

The second phase of the study compares the audience sizes, demographics, costs and recall levels of product placements within motion pictures to advertising on television and sponsored trailers. This analysis is limited to information documented in secondary sources and figures manufacturers are willing to disclose.

Primary research will generate the recall levels of a sample of existing product placements within recent motion pictures. Limited budget and time constraints dictated an audience sample size of 304 collected from six various movies. The movie viewers tested were all from theatres in Pittsburgh, PA. It may have increased reliability to include respondents from across the country, but Pittsburgh is representative of an urban center and the random sample drawn was comparable to demographics documented for nation-wide movie viewers.

The quantification phase of the study used standard Burke methodology to determine day after recall levels of brand name products appearing in motion pictures. Analysis was employed to determine if the recall levels are significantly different depending on the way the product was integrated into the movie plot. As when analyzing each test variable, the assumption was 
made that this integration variable is what will influence recall levels. It is difficult to design a test which controls for additional variables that are inherent within the placement. There are probably numerous variables which influence memorability; some which researchers will never hypothesize. Additional potential influencing variables which are not addressed in this project are discussed in the section outlining suggestions for further research.

For instance, some placements receive additional promotion through advertising in other media or point-of-purchase displays. These front and back-end promotions are becoming more prevalent. The contextual nature of the scene may affect recall. Research of these factors is suggested if the effects of product placement are to be fully understood. Research in this area may also be necessary before this type of brand name exposure can be fully exploited by manufacturers.

Admitted, the only reliable conclusions which can be drawn from this study are that some types of product placements are being remembered and that the day-after brand name recall is higher for some placements than others. This researcher hopes that the many and the obvious limitations within this study are recognized by other researchers and practitioners who take it upon themselves to improve upon this study or develop more sophisticated tests to analyze this unexplored advertising technique. 


\section{Definition of Terms}

Product Placement -- The inclusion of a brand name product package, signage, or other trademark merchandise within a motion picture, television show or music video.

Communication effectiveness -- The degree to which a message achieves a predetermined objective. For the purpose of this study, effectiveness will be based on respondent's noting of the placement and measured by frequency of day-after brand name recall. A brand name which receives a recall score of less than $10 \%$ will be considered insignificant communication. 10-19\% will be considered significant. $20-29 \%$ brand name recall will be considered effective communication. $30 \%$ recall and over will signify a very successful placement.

Cost-per-thousand (CPM) -- Standard figure used by advertisers to compare cost efficiency of media vehicles. It is the cost for reaching 1,000 consumers with an advertisement multiplied by 1000 divided by total audience members . 
Burke Day-After Recall Report -- Study done by Burke Marketing Research, Inc. Random phone interviews determine how well television commercials communicated by ascertaining how many people can remember the commercial 24 hours after it was aired.

Brand Name Exposure -- The appearance of a trademark whether it be on a product package, sign or clothing within a medium that is viewed by a mass audience.

Sponsored Trailers -- Advertisers' message which is shown before the feature film in selected theatres. They must be entertaining and usually last 60 or 90 seconds.

Memorability -- A characteristic quality inherent in a product placement which describes how well consumers/viewers can remember the brand names' appearance. 


\section{METHODOLOGY}

To fully explore the possible advantages and disadvantages of a manufacturers' product appearing in a motion picture, a two - phase study was executed. The first was qualitative in nature. A comprehensive literature review and interviews with professionals provide a descriptive background and informed insight concerning the communication message associated with a product placement.

Phase one results were based on a secondary literature review which identified examples of past product placements and provided an explanation as to how these arrangements transpire.

Phase one also provides expert opinions from those involved in product placement. Letters requesting interviews were sent to a sample of professionals within top Fortune 500 companies, major motion picture studios, product placement companies, and advertising agencies. Conference calls with those professionals who responded, were designed based on the expertise of the interviewee and provided experienced judgement concerning the communication effects of a brand name product's appearance in a motion picture from a variety 
of perspectives. Interviews were completed with brand managers, marketing, advertising and research directors, movie producers and product placement account representatives.

Phase two was designed to provide quantified data that can be used to analyze statistically the communication effects of brand name exposure within motion pictures. The objective was to provide useful information for those involved with this "advertising" technique so that effective decisions can be made.

The communication effectiveness of product placement was analyzed based on aided brand name recall scores from six movies. Respondents were chosen using a systematic random sampling. Every third person waiting in ticket lines to see the movies in the study was approached and asked if he/she would be willing to share his/her opinions of the movie he/she was about to see. Respondents were not informed as to the exact nature of the study so as to limit the sensitization of their viewing behavior. The goal was to elicit responses following a natural theatre experience.

Names and phone numbers were collected so that telephone interviews could be conducted the following day.

Five call - backs were used to limit the bias instituted by respondents not at home. Three hundred fifty names were collected and three hundred four 
interviews were completed resulting in a completion rate of $89 \%$.

Six movies showing in Pittsburgh, PA between April and June, 1987 were chosen based on their containment of varying types of product placement and varying story formats. Prior to interviewing, each movie was previewed and each appearance of a brand name was coded as to its integration into the movie plot as well as the time the brand name was exposed on the screen. The different ways products appear in films were categorized into different "types."

Type 1: Visual and verbal, implied actor endorsement - Product package is shown and brand name is mentioned in the dialogue.

Type 2: Visual implied endorsement -- Product appears in such a way as to insinuate actor endorsement.

Package receives equal camera attention.

Type 3: Background Prop -- Product visible, but in no way associated with the actor or scene in which it appears.

Type 4: Logo or brand name placement -- Product package is not shown, but brand name or trademark appears on clothing or signage.

Type 5: Verbal endorsement- brand name is mentioned in the dialogue, but product is not shown.

Various lengths of exposure were divided into five time categories based on the number of seconds the 
brand name appeared on the screen: (1)0-3 seconds; (2) 4-10 seconds; (3)11-15 seconds; (4)16-29 seconds; and (5) 30 seconds and above.

Five appearances of brand names within each movie were then chosen for study based on researching a representative selection of product placements. The placements chosen for analysis differed on several dimensions including duration, integration and product category. (See Table 1)

The movies chosen for the study represented various entertainment classifications -- adult comedy, teen comedy, adult action drama, teen action drama and horror.

\section{Questionnaire Design}

Because of the difficulty in getting a large number of people stopped and interviewed in a theatre, a questionnaire to be administered over the phone was chosen as the data-collecting instrument. This would also provide day after recall frequencies which could be used for comparisons with documented day - after recall for television commercials and sponsored trailers.

The questionnaires for each of the six movies in this study follow the same format. The questionnaires were designed first to discover if the respondent had 
seen the movie more than once so that the number of times the movie was viewed could be cross-tabulated with recall frequencies to determine if repeat viewing had a significant relationship with frequency of correct brand name recall.

Chi-square is the test statistic employed for each variable test within the present study. A .05 significance level, $\mathrm{P}($ recall $) \leq .05$, was chosen as evidence to reject the null hypothesis.

The second question asked the respondent to rate the movie on a scale of one to five with five being the best. These responses would determine if liking of the movie had any significant relationship with ability to accurately recall brand names appearing in the movie.

The respondent was then asked if he remembered seeing any brand name products or merchandise appearing in the movie to determine unaided recall frequencies.

Aided recall was tested using the five product placements chosen from within each movie. One researcher conducted all the interviews. Remarks were limited to the questionnaire so there was consistency in the interviewing procedure.

The respondents were cued by describing the scene in which the brand name appeared and indicating the product category, i.e., soft drink, snack food, automobile. Memorability of the placements was coded 
as correct brand recall, incorrect brand recall, or cannot recall.

Last, the respondent was asked to categorize himself as to product usage for the five brand names. Responses were coded as loyal user, frequent user, rare user, trial user, or nonuser. This data was collected to determine if past product experience was related to brand name recall. Cross-tabulations were executed and chi square tests employed to test for significant differences in recall based on past product usage.

Demographic data was also recorded to discover if frequency of recall was significantly different for males and females. Cross-tabulation analysis was implemented for recall and age segmentations within the sample: 12-17 years, $18-25$ years, 26-39 years and 40 years and older.

Respondents were not aware of the "time" and "type" precategorization of the placements they were asked to recall. However, this information was coded into the survey data so that recall frequencies could be analyzed according to these variables. Cross-tabulations were used to examine relationships between recall frequencies of each placement and "time" and "type" categories.

Also, all the placements across the six movies were grouped together into respective variable categories. For instance, all Type 1's were grouped 
together and all Type 2's were grouped together, etc. All Time 1's were grouped together and all Time 2's were grouped together, etc.

Average recall frequencies for each category were then established.

Summarizing quantified methodologies, a Statistical Analysis System program,(SAS), was utilized for data analysis. Correct brand name recall, incorrect brand name recall and cannot recall frequencies were established for each placement.

A cross-tabulation program provided analysis between recall frequencies and variables examined -number of times the movie was viewed, liking of the movie, past product usage, seconds of brand name exposure, type of integration into the movie plot, sex and age segmentation.

Chi square tests were the criteria to determine if the differences observed in recall frequencies were significant based on manipulation of each of test variables. Significant difference was defined as a five percent or less probability that the observed recall variance occurred by chance. $(\mathrm{P}($ recall $) \leq .05)$ This would suggest that the variable we were observing influences the sample to the point that it is no longer representative of the original population. In other words, the independent variable did have an effect in determining correct recall. 
All percentages were rounded up for easier discussion and table representation. 


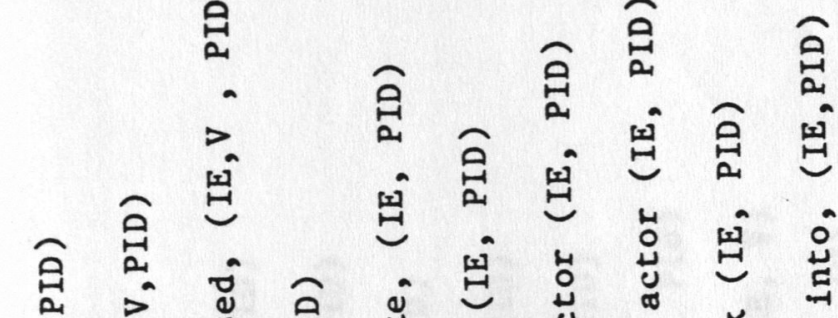

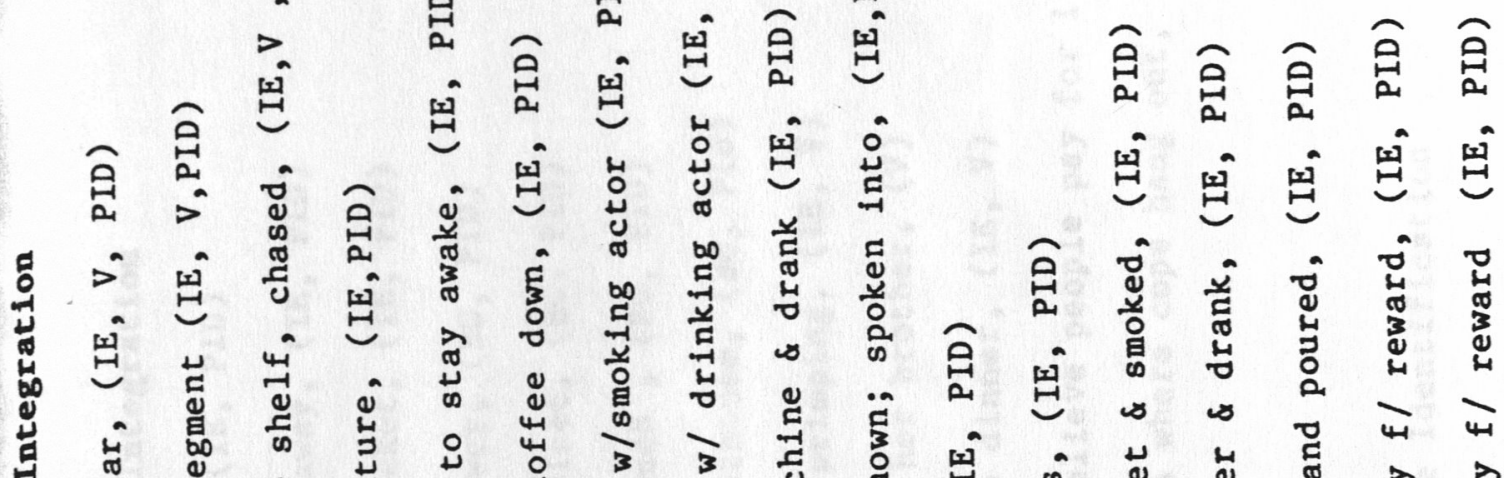
-

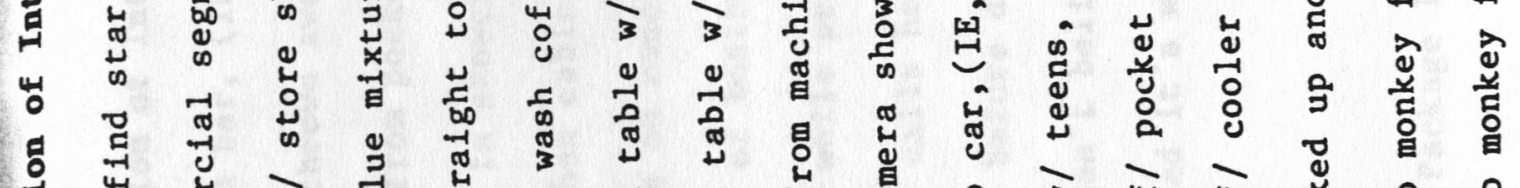

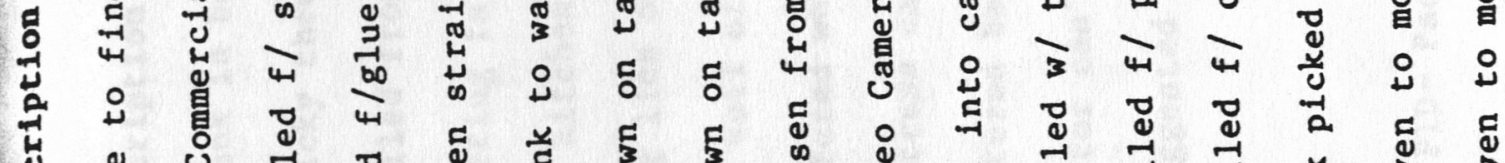

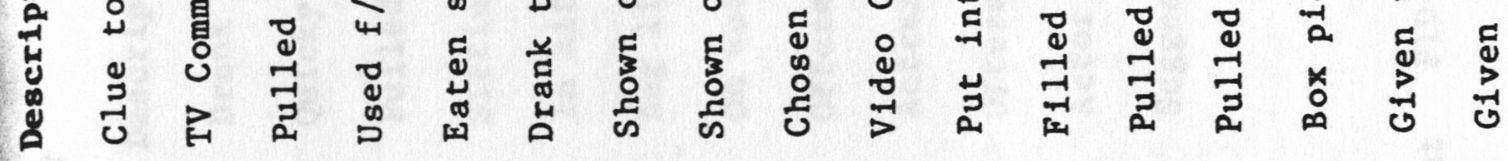

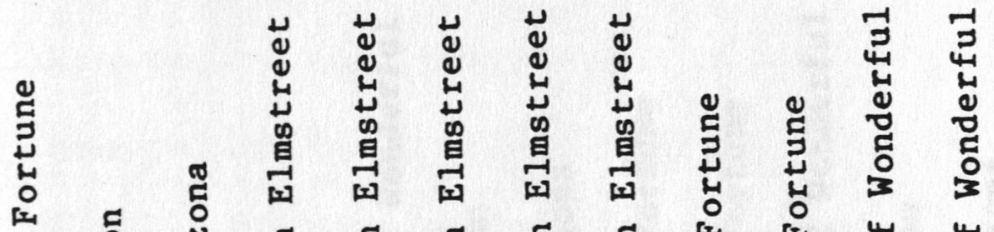

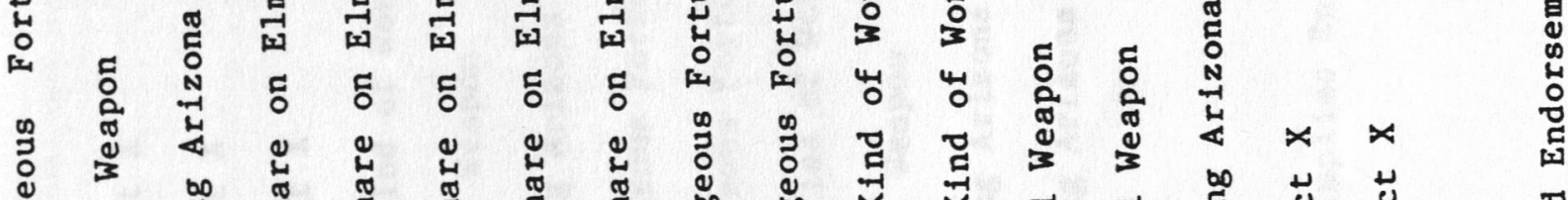

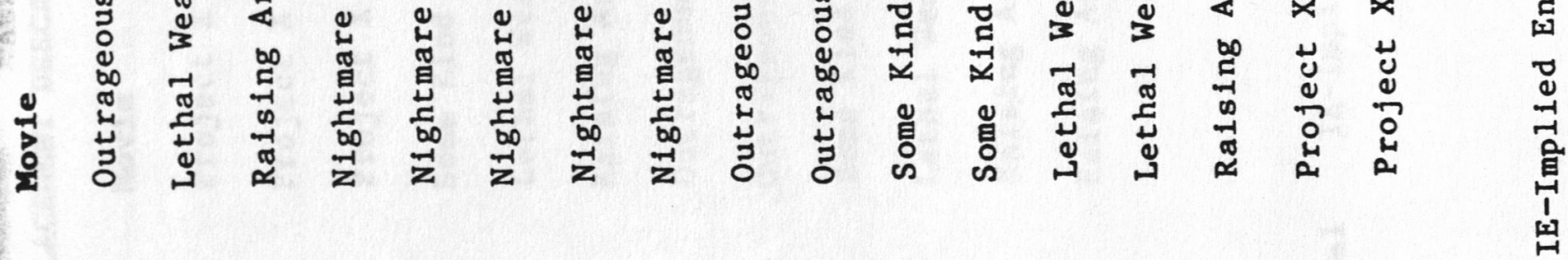

$\dot{\vdots}$

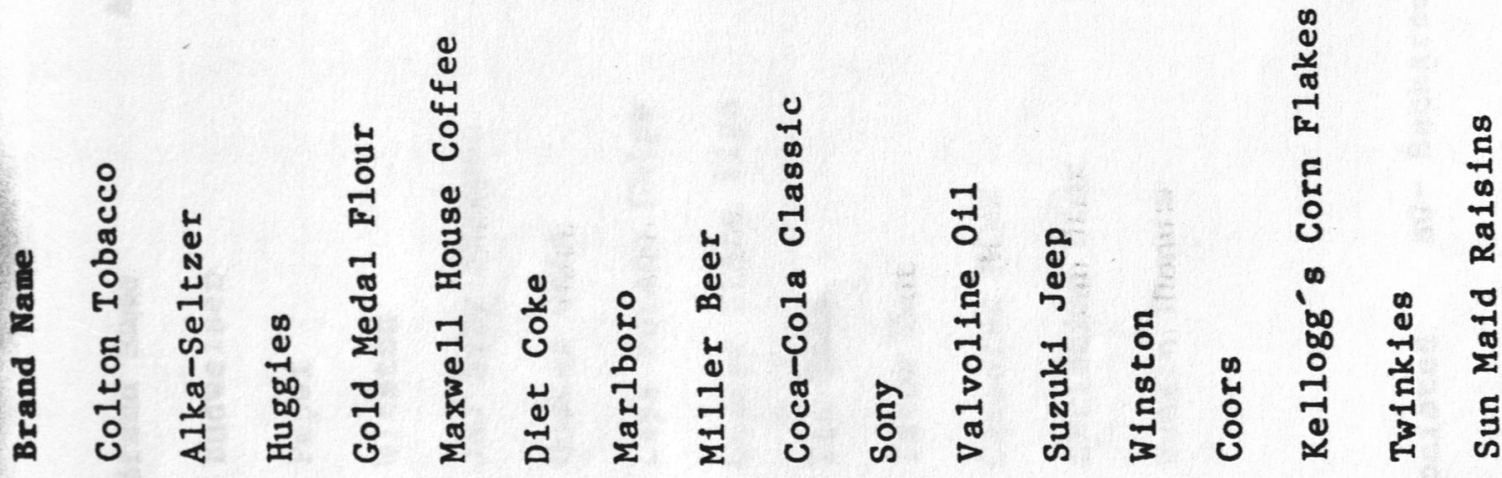

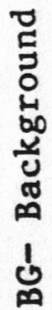
"̃ 


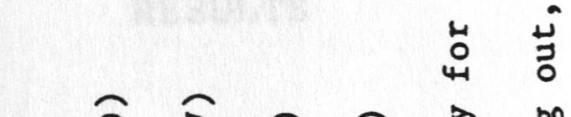

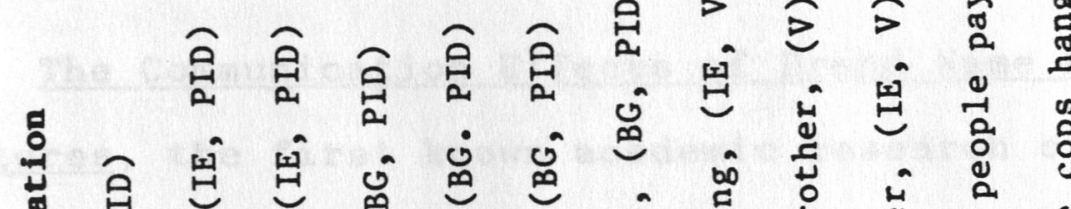

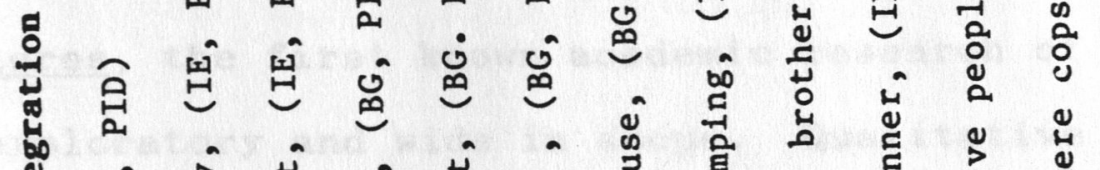

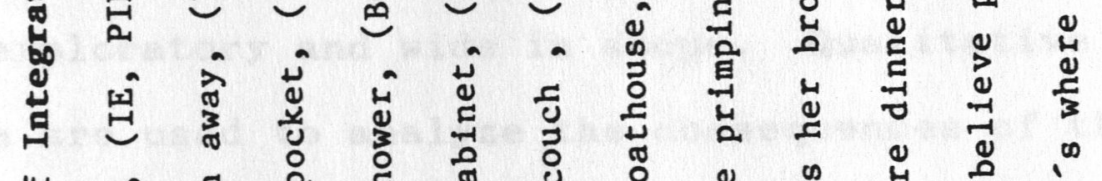

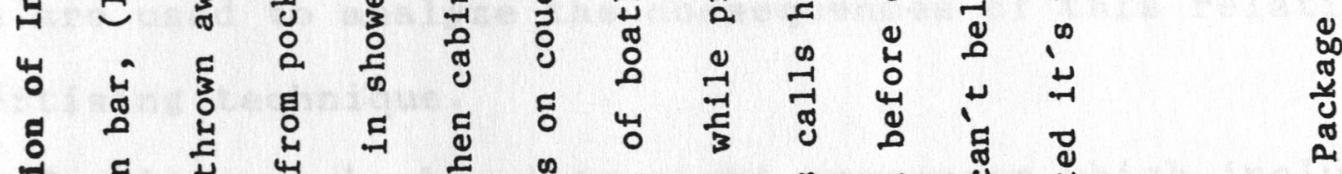

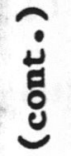

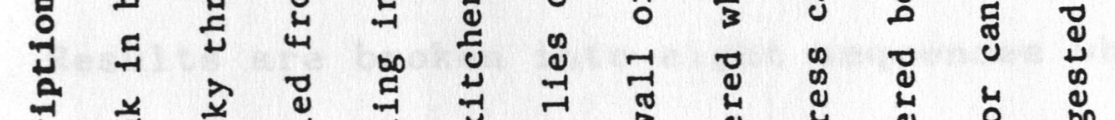

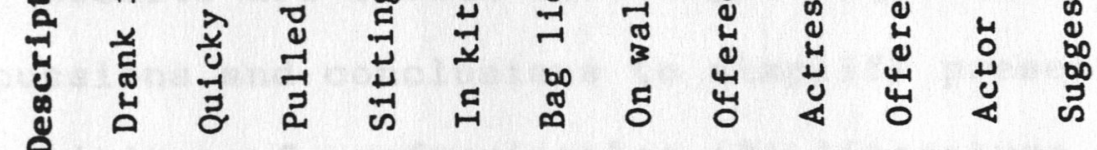

宫

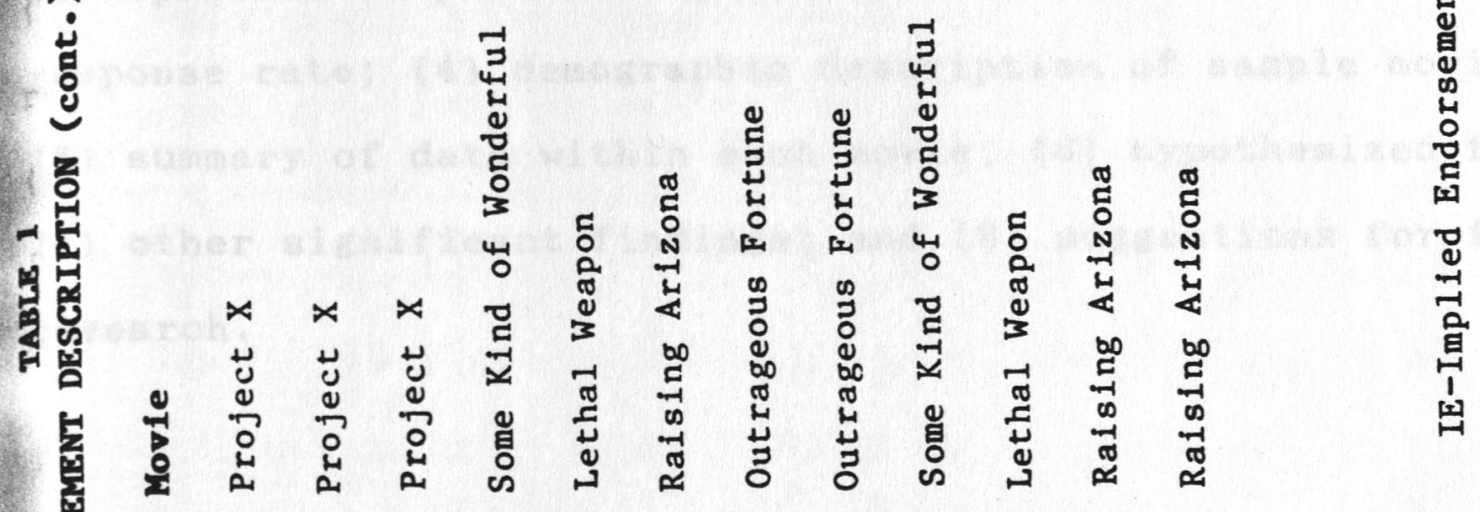

苟

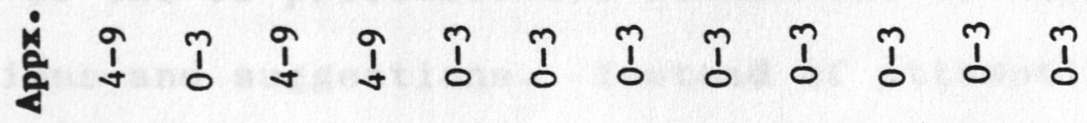

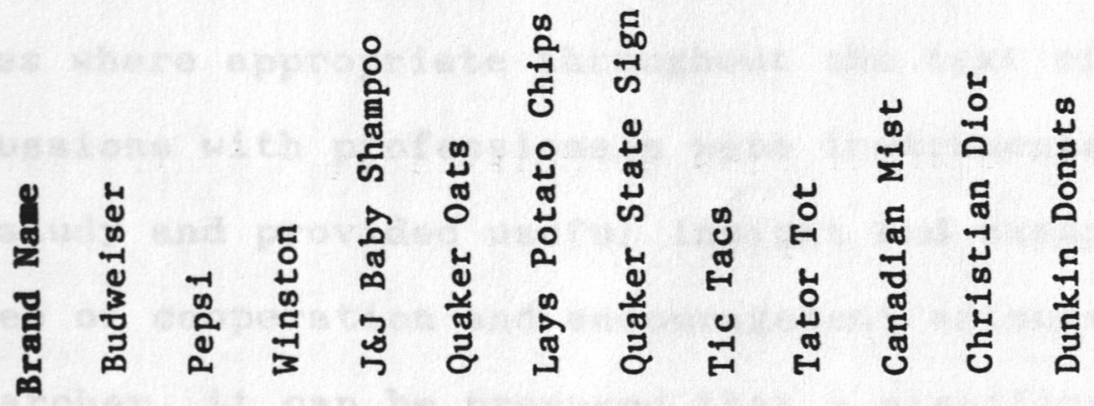

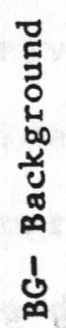

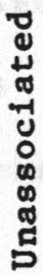

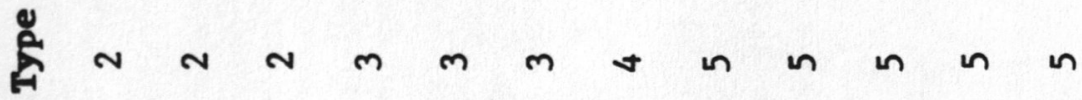


RESULTS

The Communication Effects of Brand Name Exposure in Motion

pictures, the first known academic research of product placement, is exploratory and wide in scope. Qualitative and quantitative data are used to analyze the consequences of this relatively new advertising technique.

Results are broken into eight sequences which include discussions and conclusions to simplify presentation of the data: (1) opinions of professionals; (2) literature review; (3) survey response rate; (4) demographic description of sample movie-goers; (5) summary of data within each movie; (6) hypothesized findings,

(7) other significant findings; and (8) suggestions for further research.

\section{Interviews With Professionals}

Of the 32 professionals contacted, 19 responded and provided opinions and suggestions. Instead of attempting to derive conclusions based on content of interviews, it was decided to use quotes where appropriate throughout the text of the report.

Discussions with professionals were instrumental in the design of the study and provided useful insight and examples. Based on the degree of cooperation and encouragement extended to the researcher, it can be presumed that a significant interest in the 
effectiveness of product placement exists among those involved in this advertising technique. In fact, many of those professionals who responded indicated a desire for a final report of study results.

\section{Review of Literature}

This study began with a review of literature. It seems unnecessary to include results based on this aspect of the study since a section exists with this title. However, it is justified to discuss the importance of the analysis of documented articles. This served as a starting point which launched pertinent inquiry. In fact, within this study, the literature review provided the problem statement and the main objective of the project. Since there was no research documented within the articles reviewed, the objective became to provide the first quantitative study from which others would ultimately transpire.

\section{Response Rate}

of the 350 first names and phone numbers collected in Pittsburgh theatres, there were 304 day-after movie-viewing interviews completed. This yields a total response rate of 89 percent. 
Three of the phone numbers called were disconnected or no longer in service. Three numbers were at homes where the names I was given did not live. Forty-six of the potential respondents were not reached after five call backs and thus were removed from the study.
All useable questionnaires were complete except for five questions. Blanks were coded into the computer for these questions during statistical analysis. 
Demographic Description of Sample

The respondents interviewed closely represent the demographics documented for American movie viewers. A 1985 report entitled "Movie Going in the US" analyzed audience trends and found that fully 85 percent of movie admissions is accounted for by people age 12-39.30 The 12-41 year old respondents accounted for 93 percent of the sample within this project. (See Table 2)

A 1984 Simmons Market Research study indicated that the 18-34 age group represents 56 percent of the movie audience composition. ${ }^{31}$ Interestingly, 56 percent of this project's sample were in the same demographic.

Secondary sources provide evidence which indicates the sample drawn for recall testing is representative and observations may reliably be applied to the general population of movie-goers.

Women accounted for 59 percent of the research sample. No evidence could be found to substantiate the chances of this representing a universal trend. Women were the predominant viewers in every movie chosen for review except for Project $\mathrm{X}$ within which women accounted for 48 percent -- a near even distribution. 
TABLE 2

Sample Description/ Age by Sex

$$
\mathrm{N}=304
$$

\section{Age Groups}

$$
12-17
$$$$
18-23
$$$$
24-29
$$$$
30-35
$$$$
36-41
$$

$42 \&$ up

TOTAL
Sex

Male

$6 \%$

$13 \%$

$16 \%$

$19 \%$

$12 \%$

$8 \%$

$3 \%$

$4 \%$

$3 \%$

$41 \%$
Percent of Total

$19 \%$

$35 \%$

$18 \%$

$13 \%$

$8 \%$

$7 \%$

$100 \%$ 


\section{Hypothesis Statements}

Null Hypothesis 1 - The cost to reach 1,000 television viewers or movie viewers through sponsored trailers is lower than that of product placement.

Ho: $X(t v) \& X(s t)<X(p p)$

Alternative Hypothesis 1 - Product placements are cost efficient when measured with the advertising standard of cost-per-thousand (CPM) and compared to television advertising and sponsored trailers.

$$
\text { H1: } X(p p)<X(t v) \& X(s t)
$$

Null Hypothesis 2 - Product placement in motion pictures is not an effective technique for manufacturers to gain brand name exposure. The average day-after brand name recall will be less than $20 \%$.

$$
\text { Ho: } \mathrm{x}<.20
$$

Alternative Hypothesis 2 - Product placement in motion pictures is an effective way for manufacturers to gain memorable brand name exposure. The average day-after brand name recall will be at least $20 \%$. 
* The symbolic representation of Hypotheses 3 demonstrates that for the null not to be rejected, all recall values will be the same regardless of the variable tested. Supporting the alternative indicates that one or some of the recall values may be significantly different. This representation applied to Hypotheses $3-9$.

Null Hypothesis 3 - Brand name recall is independent of way the brand name is integrated into the movie plot. (Chi-square tests will determine whether or not observed changes in recall are real or observed by chance. A $95 \%$ confidence level, $\alpha=.05$, for each chi-square test within the study.

Ho: $p($ row $i$ column $j)=p($ row $i)$ p(column $j)$ for all $i, j$

Alternative Hypothesis 3 - Brand name recall will be significantly different depending on the way the brand name is integrated into the movie plot. For the purposes of this study product placements have been divided into 5 categories. (See Methodology chapter for complete descriptions of 5 types.) H1: $P($ row $i$ column $j)=p($ row $i)$ (column $j)$ for some $i, j$ Null Hypothesis 4 - Recall is independent of placement type. Alternative Hypothesis 4 - Type 1 placements will receive the highest frequency of brand name recall. 
Type 2 will receive the next highest recall level followed by 3 and 4 , with Type 5 receiving the lowest level of recall- less than 10 percent and therefore deemed ineffective communication. Null Hypothesis 5 - Correct brand recall is independent of repeat viewing .

Alternative Hypothesis 5 - Correct day-after brand name recall will be significantly different based on the number of times the movie was viewed by the respondent.

Null Hypothesis 6 - Brand name recall is independent of gender.

Alternative Hypothesis 6 - As found with day-after recall for television commercials, levels of recall will be significantly different between women than men.

Null Hypothesis 7 - Brand name recall is independent of age.

Alternative Hypothesis 7 - There will be a significant difference in recall between the demographic age segments of the sample.

Null Hypothesis 8 - Brand name recall is independent of exposure time. 
Alternative Hypothesis 8 - The time (in seconds) a brand name is exposed during a film will be positively correlated with average brand name recall.

Null Hypothesis 9 - Brand name recall is independent of brand name usage.

Alternative Hypothesis 9 - There will be a significant difference between correct brand name recall and the respondent's level of product usage. The respondent will categorize himself as a loyal, frequent, rare, trial, or non-user of the brand names being tested.

Hypotheses Analysis

Some of the proposed hypotheses could not be adequately tested within the confines of this thesis. As noted in the limitations section, acquiring exact costs per product placement and establishing accurate audience sizes is difficult if not impossible by someone outside the industry. Therefore, reliably supporting or rejecting Hypothesis 1 regarding cost efficiency was impossible within this study. However, there is substantial evidence indicating that product placements are cost efficient when compared to television commercials. Diener/Hauser/Bates 
Co., Inc. indicates in their sales kit that the average movie theatre attendance is $20 \mathrm{million.}$ (Source: Variety)

When considering ultimate movie-viewers, one must now take into account the inevitable video cassette audience and cable television viewers. With these audience members added, Fred Stuart, president of F.S. Cameron placement firm, estimates the average motion picture is seen by 36 million people worldwide. 32 Unique Product Placement documents CPMs as low as two cents for major films such as E.T.

The premiere showing on network television is seen by 30 million viewers on average. (Source: A.C. Nielsen) It should be noted here that these audience size estimates do not reflect how many viewers actually saw the brand name on either the television or movie screen.

Product placement costs divulged in magazine articles and cited in product placement firm sales kits are low in comparison with network commercial time costs found in SRDS. A manufacturer may pay between $\$ 10$ and $\$ 50$ thousand dollars per film placement. A 30 second commercial on The Cosby Show costs $\$ 380,000$ and this amount does not include production costs. 33 With these very general characteristics factored in with product placement brand recall scores, motion pictures appear to be a worthwhile medium to consider in advertising budget allocation.

Product placement cost efficiency may also be compared to that of sponsored trailers shown in theatres. Just as product placement representatives emphasize, entertainment comes first 
with these in-theatre commercials. The going rate for advertisers is $\$ 500,000$ for a 60 -second commercial which is an $\$ 18$ cost-per-thousand. This is approximately 25 percent more expensive than the average television commercial..$^{34}$

Using standard Burke methodology as was used in this project, Screenvision Cinema Network documents a day-after recall for theatre commercials which averages 87 percent. 35

Considering the high costs of sponsored trailers and the selection process -- only certain product categories are conducive to theatre commercials and they must be deemed entertaining -- product placement within motion pictures is still an attractive alternative form of advertising. Available evidence at least partially supports Alternative Hypothesis 1 - product placements are cost efficient when compared to television commercials and sponsored trailers.

Hypothesis 5 , which concerned the relationship between brand name recall and times the respondent viewed the movie, could not be reliably supported or rejected based on the data collected. The movies chosen for analysis were seen more than once by only 16 of the respondents and these persons viewed the movie only twice. Therefore, it was decided to omit analysis of this variable.

Experimental evidence was sufficient to reject Null Hypothesis 2 which asserted that product placement in motion pictures is ineffective communication. 
Alternative Hypothesis 2 was thus accepted. Product placement in motion pictures is effective communication based on the definition of "effective" which was outlined in the project. It was hypothesized that average recall would be at least 20 percent. $\quad x \geq .20$ The average correct brand name recall of the thirty placements analyzed was 38 percent. (See Table 3 ).

Day-after brand name recall ranged from 0-93 percent. If one uses 20 percent as a benchmark from which to measure effectiveness, 67 percent $(20)$ of the placements being analyzed were effective.

The Burke Marketing Research firm documents an average recall of 20 percent for all television day parts. ${ }^{36}$ when compared to this, a majority of the sample placements were at least as effective as the average television commercial.

The 20 percent recall seems prevalent in documented research. In 1963 the Wichita Eagle Beacon found 23 percent of 2800 telephoned prime-time adult viewers correctly named the last advertised product or brand. In 1965, the Bureau of Advertising found only 18 percent of 1000 telephoned prime-time adult viewers correctly named the last advertised brand, but another 14 percent named a brand advertised in the telecast. ${ }^{37}$ It must be recognized that these tests were conducted immediately following the broadcasts, while the research conducted in this thesis addressed the day-after memorability of brand names. BBDO's "Channel One" studies included prompting comparable to recall aids instituted in this research. Respondents were 
prompted with program descriptions and product classes and no more than 40 percent of the program audience remembered the brand advertised and only 25 percent could play back any commercial content. 38

Thus, it may be inferred that product placement's effectiveness is comparable to television commercial's so far as memorability is concerned. This is even though most placements are not nearly the 15 or 30 seconds of concentrated endorsement inherent with television advertising.

Null Hypothesis 3 , brand name recall is independent of the way the brand name is integrated into the movie, was rejected based on study results.

Alternative Hypothesis 3 suggested a significant difference in recall depending on ways the brand name was integrated into the movie plot. Data collected indicates that this independent variable influences recall to a statistically significant degree. $\mathrm{P}($ recall $) \leq .05(\mathrm{Chi}-$ Square $=136$, Probability $=0.000)($ See Table 4)

It was also hypothesized that a placement in which there was package identification as well as verbalization of the brand name would receive the highest recall. Data collected supported this hypothesis with Type 1 placements being accurately recalled by 57 percent of the respondents.

Type 5 placements, a verbal endorsement with no logo or brand name identification, was hypothesized to receive the lowest correct recall -- less than 10 percent. Observations did not 
TABLE 3

Placement By Recall Bffectiveness

Recal1 Range- 0-937

Average Recal1-387

0-9\% Recall Score/(Insignificant)

Lays Potato Chips (0\%)

Valvolene 0 il (2\%)

Quaker Oats (3\%)

Gold Medal Flour (3\%)

Sony Video Camera (4\%)

Pepsi ( $8 \%$ )

Quaker State (8\%)

11-19\% Recall Score/(Significant)

Mar1boro (13\%)

Winston (13\%)

Canadian Mist (15\%)

20-25\% Recall Score/(Comparably Effective)*

Johnson \& Johnson Baby Shampoo (20\%)

Colton Tobacco (21\%)

Miller Beer (22\%)

Suzuki Jeep (24\%)

Coke Classic (25\%)

267-50\% Recall Score/(Effective)

Coors Beer (36\%)

Budweiser $(36 \%)$

Winston $(40 \%)$

Christian Dior (50\%)

517-75\% Recall Score/(Very Effective)

Tator Tots ( $54 \%$ )

Maxwe11 House Coffee (56\%)

Alka Seltzer (63\%)

Kelloggs Corn Flakes (67\%)

Twinkies ( $72 \%)$

Tic Tacs $(72 \%)$

Diet Coke $(73 \%)$

76-100\% Recall Score/(Excellent Recal1)

Dunkin Donuts (77\%)

Marlboro ( $81 \%$ )

Sun Maid Raisins ( $84 \%)$

Huggies (93\%)

*Within the range of television commercial recall scores 
TABLE 4

Placement Types by Average Recal1

\section{Placement Type}

Type 1

Verbal \& Package ID

\section{Type 2}

Implied Endorsement \& Package ID

$67 \%$

$33 \%$

Type 3

Unassociated Package ID

$92 \%$

$8 \%$

Type 4

Logo or Brand Name ID/Signage

$92 \%$

$8 \%$

\section{Type 5}

Verbal Endorsement/No Brand Name ID

$49 \%$

$51 \%$

Recall Range- $0 \%$ to $93 \%$

Average Recal1- $32 \%$

STATISTIC

DEGREES OF FREEDOM

VALUE

PROBABILITY

Chi-Square

4

136

0.000 
support this hypothesis. In fact, this type of brand name integration received the second highest average correct recall -51 percent.

Type 2 placements, implied endorsement through association with an actor, received an average recall of 33 percent. These types of placements seem most prevalent within the industry and are represented accordingly in this study -- 18 of the 30 placements are categorized as Type 2 .

Type 3 placements, unassociated background props, were correctly recalled by 8 percent of the respondents. Type 4 placements, logo or brand name signage as props, were also recalled by 8 percent of the respondents. Based on inferences from this study, a brand name product package appearing as a background prop with no attention drawn to it by an actors use or scene importance, can be expected to receive insignificant recall frequency.

It may also be inferred that a placement consisting of a brand name or a product logo appearing on clothing, signage, etc., will also receive insignificant audience recall. It should be noted here, that these types of placements are also used extensively because they are appropriate for many movie scenes, i.e. neon beer signs in bars, logo t-shirts on actors. Unfortunately, only one such placement was represented within this study -- Quaker state signage. Since these placements usually are unassociated background props, it may be possible to 
classify them as Type 3. Regardless, the projected audience recall is low based on this study.

Illustration 1 represents the intervals of brand name recall for each placement type with which there is 95 percent confidence that they will contain the true value for the population parameter. These ranges provide reliable means with which to estimate expected recall based on the way a brand name is integrated into the movie plot. Thus, a manufacturer can predict what percent of the movie audience could likely recall a brand name featured within a motion picture. These confidence intervals not only predict how effective past product placements have been; expected recall ranges per placement types may initiate a standardized cost structure or at least indicate the value of a placement while it is in the planning stages.

Cross-tabulation and chi-square analysis fail to provide evidence with which to reject Null Hypothesis 6 which suggests brand name recall is independent of gender.

Male respondents correctly recalled 36 percent of the brand names when aided. Female respondents accurately named 35 percent of the placements. (See Table 5) The Chi-Square probability is 0.482 . Since this is greater than the 0.05 designated as the rejection region within the study, the null hypothesis must be accepted.

However, upon closer examination of the results and controlling for placement type, a difference in which type of placements are effective with each sex is suggested. 


\section{ILLUSTRATION 1 \\ 957 CONFIDENCE IKTERVALS}

This study established the following average brand name recall confidence intervals for the five placement categories (types) tested. These intervals indicate that one can be 95 percent confident that the range expressed contains the true value of the population parameter.

$$
\text { Using Formula - } p \pm 1.96 p(1-p) / n
$$

Type 1: Verbal and Package Identification

Established Average Recal1- $57 \%+.076$ margin of error Confidence Interval- 507 to 657 Recall

Type 2: Package Identification Associated with Actors Established Average Recal1- $33 \%+.031$ margin of error Confidence Interval- $30 \%$ to $36 \%$ Recall

Type 3: Unassociated Package Identification

Established Average Recal1- $8 \%+.042$ margin of error Confidence Interval- 47 to 127 Recall

Type 4: Brand Name or Logo Identification Established Average Recal1- $8 \%+.07$ margin of error Confidence Interval- 17 to 157 Recall

Type 5: Verbal Endorsement by Actor Established Average Recal1- $48 \%+.06$ margin of error Confidence Interval- $42 \%$ to $54 \%$ Recall 
TABLE 5

Sex by Recall

\begin{tabular}{l|cc} 
Sex & \multicolumn{2}{|c}{ Recall } \\
Male & Incorrect & Correct \\
Female & $64 \%$ & $36 \%$ \\
\hline
\end{tabular}

\begin{tabular}{llrc} 
STATISTIC & DF & VALUE & PROBABILITY \\
\hline Chi-square & 1 & .495 & .482
\end{tabular}

TABLE 6

Correct Recall/Sex By Placement Type

\begin{tabular}{l|rrrrr} 
Sex & \multicolumn{7}{|c}{ Type } \\
\hline & 1 & 2 & 3 & 4 & 5 \\
\hline Male & $66 \%$ & $35 \%$ & $3 \%$ & $9 \%$ & $47 \%$ \\
Female & $50 \%$ & $32 \%$ & $11 \%$ & $6 \%$ & $54 \%$
\end{tabular}


(See Table 6) Males are much more likely to remember the placements with a visual and verbal component $(66 \%)$ in comparison to the other types of placements. Women have the highest recall for Type $5(54 \%)$ which involves a verbalization of the brand name but no package identification. This provides interesting implications consistent with research involving the different ways men and women process information.

Data indicates that males and females do not have similar brain development. ${ }^{39}$ Each side of the brain serves different functions so that the two hemispheres contribute differently to the perception and organization of information. Men are more inclined to rely on the right hemisphere of the brain. The right hemisphere is visually oriented. Information is processed in a holistic manner. This type of information processing is evident in this study since men had the highest level of recall for Type 1 placements and scored higher than women on Type 2 placements. It is the left side of the brain that is more verbally oriented. This is again consistent with observations from the present study - - women had the highest correct recall for verbal brand name placements. Women are more apt to integrate the left and right side of the brain in learning and thinking. This may explain why women had a lesser variance in their average recall for the various types of placements.

More extensive testing may prove insightful and indicate techniques to execute more effective product placements with which to influence each sex. 
The data collected and statistical analysis executed was adequate evidence with which to reject Null Hypothesis 7 , -brand name recall is independent of age. (See Table 7) $P($ recall $) \leq .20($ Chi-Square $=35$, Probability $=0.000)$

Alternative Hypothesis 7 is thus accepted -- brand name recall is significantly different between movie-viewer age segments.

Analysis of this variable provides additional interesting implications.

The age segmentation of the sample population is representative of the demographics documented for movie viewers. Those respondents who are 42 years of age and older constituted 7 percent of the sample. These respondents had an average recall of 12 percent while the average for all age groups was 35 percent. (See Table 7) A recall which is nearly three times lower than average may provide warranted concern for manufacturers of products which are marketed to this age group. Null Hypothesis 8 , brand name recall is independent of seconds of brand name exposure, can be rejected based on the analysis within this project. However, the study is weak in regards to the inferential analysis of this variable. The seconds of exposure for each placement was roughly counted and arbitrarily categorized. Therefore, there is low confidence in the conclusions which may be drawn. The Chi-Square analysis suggests a significant difference in recall between the time 
TABLE 7

Average Recall By Sample Age Segments

\begin{tabular}{|c|c|c|}
\hline $\begin{array}{l}\text { Age } \\
12-17\end{array}$ & $\begin{array}{l}\text { Incorrect Recall } \\
72 \%\end{array}$ & $\begin{array}{c}\text { Correct Recall } \\
28 \%\end{array}$ \\
\hline $18-23$ & $66 \%$ & $34 \%$ \\
\hline $24-29$ & $63 \%$ & $37 \%$ \\
\hline $30-35$ & $70 \%$ & $30 \%$ \\
\hline $36-41$ & $63 \%$ & $36 \%$ \\
\hline $42 \& U p$ & $88 \%$ & $12 \%$ \\
\hline
\end{tabular}


categories. $\mathrm{P}(\mathrm{recall}) \leq .05$ (Chi-Square $=33$, Probability $=$ 0.000 ) (See Table 8)

The researcher admits a lack of confidence in the reliability of the data also due to the selection of placements to analyze. Unfortunately, there was only one placement with an exposure time of $16-29$ seconds and its recall score was 21 percent. Since it must be represented in time analysis, this placement breaks the increasing trend of recall observed as seconds of exposure increases. Further analysis is suggested since seconds of exposure may be a powerful mediator of effectiveness. Also, seconds of exposure is a factor involved when some product placement fees are arranged. Further research is needed to reliably support or reject the hypothesis of a positive correlation between correct brand name recall and seconds of brand name exposure.

Null Hypothesis 9 suggests that brand name recall is independent of brand name usage classification. Chi-square analysis provided evidence with which to reject the null. See Table 9. $P($ recall $) \leq .05$.

Alternative Hypothesis 9 is accepted -- brand name recall is significantly different based on respondents' indication of brand name usage. The average correct recall ranged from 30 percent for non-users to 42 percent for frequent users.

There is no indication of a directional relationship --

brand name recall being highest for loyal and lowest for non-users. 
TABLE 8

Seconds of Brand Name Bxposure by Average Recall

Time 1

0-3 Seconds

$67 \%$

$33 \%$

Time 2

4-9 Seconds

$65 \%$

$35 \%$

Time 3

10-15 Seconds

$62 \%$

$38 \%$

Time 4

16-29 Seconds

$79 \%$

$21 \%$

Time 5

30 Seconds \& Up

$41 \%$

$59 \%$

Recall Range- 0\% to $93 \%$

Average Recall- $37 \%$

STATISTIC

DEGREES OF FREEDOM

VALUE

PROBABILITY

Chi-Square

4

33

0.000 
TABLE 9

Average Correct Brand Name Recall By Brand Name Useage

Brand Name Useage

Loya1

Frequent

Non

Trial

$66 \%$

$61 \%$

$58 \%$

$60 \%$

$40 \%$

Incorrect Recal1

Correct Recall

$39 \%$

$70 \%$

$30 \%$

\section{STATISTIC}

Chi-Square
DF

4
VALUE

19.72

PROBABILITY

0.0001


In fact, the placement which received the highest recall, Huggies - 93 percent, had a rather low usage rating - 18 percent. The placement with the lowest recall, Lays Potato Chips - 0 percent, had a high usage rate - 98 percent.

This closer analysis dictates a need for more research concerning product usage as a mediator of product placement effectiveness.

Summarizing, the findings show emerging empirical links between correct brand name recall and the intrinsic variables of product placements within motion pictures.

It also appears that various demographic segments of movie viewers are more likely than others to correctly recall brand names appearing within films.

The confidence intervals generated from the recall frequencies also exhibit, to a certain degree, a predictive power. (See Illustration 1)

Replications of this work are needed to further substantiate findings. It would prove useful to apply additional statistical tests to analyze correlational and directional relationships.

This project results in empirical evidence which indicates the potential advertising power of product placements within motion pictures. It is now up to practitioners to utilize these findings and recognize the need for further analysis of this technique to gain favorable brand name exposure. 


\section{OTHER SIGNIFICANT FINDINGS}

There are many studies documented which analyze the effects of consumer attitudes toward advertising memorability. This affective involvement condition has been credited with influencing communication effectiveness as well as purchase intentions. 40 This notion is consistent with the growing awareness among psychologists of the almost automatic nature of basic affective processing.

The questionnaire in the study asked the respondents to rate each movie on a scale of one to five with five being the best in accordance to their liking of the movie. Table 10 represents the average recall for each of the rating scores. The chi-square statistic was once again the criteria for analysis. The probability determined was .021, indicating a significant difference in recall.

$P($ recall $) \leq .05$

Upon inspection, however, it becomes apparent that it is the Rate 2 recall which alone dictates the difference. Before inferences are drawn based on this data, it should be noted that within this, study Raising Arizona had the lowest rate average--2.5. This movie also had the highest average recall among respondents --57 percent. This factor is likely responsible for the chi-square results. A closer examination of this variable is warranted based on the wealth of research indicating the mediating power of the affective condition. Research involving recall based on attitudes toward brand names featured within movies and 
attitudes toward product placement in general may prove insightful. 
TABLE 10

Rate By Recall

\section{Rate}

1

2

3

4

5

\section{Recall \\ Incorrect Correct}

$\begin{array}{ll}64 \% & 36 \% \\ 50 \% & 50 \% \\ 65 \% & 35 \% \\ 65 \% & 35 \% \\ 67 \% & 33 \%\end{array}$

Average Correct Recall $38 \%$

\begin{tabular}{llcc} 
STATISTIC & DF & VALUE & PROBABILITY \\
\hline Chi-square & 4 & 11.57 & .021
\end{tabular}




\section{SUGGESTIONS FOR FURTHER RESEARCH}

The primary objective of this study was to determine the effectiveness of brand name exposure in motion pictures based on day-after recall scores. From the data collected it can be concluded that product placement can be an effective exposure-gaining technique. A wide range in correct brand name recall frequencies was observed--0-93 percent. This study was but a first step in spearheading the variables which influence movie-goers' ability to note an appearance of a brand name.

To fully understand this advertising technique, more specialized and extensive research is required to analyze variables that have significant relationships with recall frequencies. A continued observation of consistent trends would substantiate conclusions. Reliable inferences could be drawn and used to predict expected recall for any placement. Also, by discovering which variables are consistently related to high recall, more effective use can be made of product placement.

This study included 30 product placements within six movies. With consideration for the study's limitations, significant and reliable information was generated. A study designed to include a larger number of placements with all types and seconds of exposure categories equally represented would provide more confident conclusions. 
A variable which may prove insightful to analyze is the respondent's brand name familiarity. It would seem this more than the respondents' usage would impact recall. It would be interesting to discover if brand names with high top-of-mind awareness consistently receive higher correct recall than brand names with low consumer familiarity.

Before a respondent views a movie, a researcher could code for brand name familiarity using a Likert Scale. Respondents could also be asked to identify brand names when prompted with advertising tag lines, claims or possibly package design depending on the objectives of the study. These scores could then be compared with the audiences' ability to note correctly the appearance of the brand names being analyzed.

The context or environment in which the brand name appears may also be relevant in the study of correct recall scores. Are placements within funny or climatic scenes consistently related to higher recall? Using an example from this project, in Outrageous Fortune, during an irrelevant dialogue, Shelly Long goes to a Coke machine, gets a Classic Coca-Cola and continues walking and talking with the can visible in her hand for over 10 seconds. A blatant placement of a universally recognized product, but only one fourth of the respondents remembered the Coke in that scene.

Manufacturers and their advertising agencies are obviously interested in how their advertising impacts sales 
of their products. It is difficult to credit overall sales to any isolated advertising effort although some articles do cite increases in sales after a product's appearance in a film. Valid data may result from a study in which respondents indicate their purchase intentions toward brand names appearing in the films being researched. Scores could be compared from before and after the movie to indicate changes in the audience's intent to buy brand names featured within the film.

At this time it seems difficult to design an adequate study regarding the cost efficiency of product placement. There are no industry standards for fees and costs incurred are difficult to discover. A majority of the manufacturers contacted considered this information proprietary. For cost analysis, dollar amounts per each placement would be needed. Cost efficiency is standardly measured using cost per thousand in other advertising media. Therefore, a standard procedure is also needed to measure audience size. Only when such standards are instituted within the industry, can comparable and thus useful CPM's be generated.

The precipitation of further inquiry and the generation of more specialized and sophisticated research projects involving product placement would in itself justify the efforts exerted within this thesis. 


\section{ENDNOTES}

p. 138 .

1"Madison Avenue Meets Hollywood," American F1lm, November, 1984 ,

2"Reese's Pieces sales blast off with E.T.," Marketing Communications, September, 1982 , p. 25.

${ }^{3}$ Interview, Jeff Coleman, Distribution, Paramount Pictures.

${ }^{4}$ Interview, Robert Blanchard, V.P. Marketing, Colgate Palmolive.

${ }^{5}$ Letter, Alice Geraux, Anheuser-Busch.

6etter, Melvin Grayson, Nabisco Brands.

7nterview, Jeffrey C. Young, Unique Product Placements.

${ }^{8}$ Diener/Hauser/Bates Co., Inc. Sales Kit, 1986 ,

9nterview, Doug Christoph, Young Adult Promotions, Miller Brewing, Co.

10"Staying Ahead of the Trends," The Hollywood Reporter, June 2, 1987, S-4.

11 Spillman, Susan, "Marketers Race to Leave Their Brand on Films," Advertising Age, July 1, 1985, p. 55.

12 Ibid.

${ }^{13}$ Pietschmann, Richard, "And Maybe He Should Be Smoking Virginia Slims," Los Angeles, October, 1981 , p. 172.

${ }^{14}$ Interview, Michael Harpster, Distribution, New Line Cinemas.

${ }^{15}$ Interview, George Ker, V.P. Advertising, Kimberly Clark.

${ }^{16}$ Citron, Rusty, "Film Promotion Council: Setting Industry Standards," The Hollywood Reporter, June 2, 1987 , p. S-17.

${ }^{17}$ Shorkey Betsy, "Kovoloff's Casting Rockets to Stardom," AdWeek, Feb. 18, 1985, pg. 20.

${ }^{18}$ Bronson, Gail, "Ads in Movies? You're Already Watching Them," U.S. News And World Report, August 20, 1984, p. 43.

${ }^{19}$ Cole, Benjamin Mark, "Madison Avenue Meets Hollywood and Vine," California Business, August 1986, p. 65.

20 op. cit., Spiliman.

${ }^{21}$ Unique Product Placement Sales Kit, 1986.

${ }^{22}$ Rotkin, Nora J., "Product Visibility in Motion Pictures," Marketing Communications, Sept. 1982, (Advertisement.) 
${ }^{23}$ Foltz, Kim, "Ads Popping Up All Over, Newsweek, August 12, 1985, p. 50.

${ }^{24}$ Bogart, Leo, "What forces shape the future of advertising research," Journal of Advertising Research, Feb/March, 1986.

25 Raymond, Charles, Advertising Research: The State of the Art, (Association of National Advertisers, Inc.), 1979, p. 200.

${ }^{26}$ Lowery, Shearon and Melvin DeFleur, Milestones in Mass Communication Research, (New York, Longman Publishing Co.,) 1983, p. 385

27 "Thorson, Ester and Rita Snyder, Journal of Marketing Research, May 1984.

${ }^{28}$ Ross, Harold L:. "Recall Versus Persuasion: An Answer," Journal of Advertising Research, 22, 1982.

${ }^{29}$ Gibson, Laurence D., "Not Recal1," Journal of Advertising Research, 23, pp. 183-196.

${ }^{30}$ Schwartz, Joe, "Americans Go To The Movies," American Demographics, Sept. 1986 , p. 60 .

31"Big Screen Ads Put Showbiz First," Television/Radio Age, May, 1986, p. 169.

32 "Psst. did you ever want your product to be a star," Advertising Age, Feb., 1982 .

${ }^{33}$ Alsop, Ronald, "More prime-time tv shows plug airlines and hotels in scripts," Wall Street Journal, May 22, 1987.

34 0p. cit., "Big Screen Ads Put Showbiz First."

35

Ibid.

${ }^{36}$ op. cit., Raymond, Charles.

${ }^{37}$ Ibid.

38

Ibid.

${ }^{39}$ Pearson, Judy, Gender and Communication, (WMC. Brown Company Publishers, )1985, pp. 145-147.

40 "The Role of Attitude Toward the Ad as a Mediator of Advertising Effectiveness: A Test of Competing Explanations," Journal of Marketing Research, Vol 23, May 1986. 


\section{SOURCES CITED}

Alsop, Ronald, "More prime-time tv shows plug airlines and hotels in scripts," Wa11 Street Journal, May 22, 1987.

"Big Screen Ads Put Showbiz First," Television/Radio Age, May, 1986.

Blanchard, Robert, Interview, V.P. Marketing, Colgate-Palmolive.

Bogart, Leo, "What forces shape the future of advertising research," Journal of Advertising Research, Feb./March, 1986.

Bronson, Ga11, "Ads in Movies? You're Already Watching Them," U.S. News and World Report, August 1986.

Christoph, Doug, Interview, Young Adult Promotions, Miller Brewing, Co.

Citron, Rusty, "Film Promotion Council: Setting Industry Standards,"

The Hollywood Reporter, June 2, 1987.

Coleman, Jeff, Interview, Distribution, Paramount Pictures.

Diener/Hauser/Bates Co., Inc. Sales Kit, 1986.

Foltz, Kim, "Ads Popping Up All Over, Newsweek, August 12, 1985.

Geraux, Alice, Letter, Anheuser-Busch.

Gibson, Laurence D., "Not Recal1," Journal of Advertising Research, Vol. 23.

Grayson, Melvin, Letter, Nabisco Brands, Inc.

Harpster, Michael, Interview, New Line Cinemas.

Ker, George, Interview, V.P. Advertising, Kimberly-Clark Corp.

Lowery, Shearon and Melvin DeFleur, Milestones in Mass Communication Research, New York, Longman Publishing Co..

"Madison Avenue Meets Hollywood," American Film, November, 1984.

Pearson, Judy, Gender and Communication, WMC Brown Publishers, 1985.

Pletschmann, Richard, "And Maybe He Should Be Smoking Virginia Slims," Los Angeles, October, 1981.

"Psst. did you ever want your product to be a star?" Advertising Age, Feb 1982 .

Raymond, Charles, Advertising Research: The State of the Art, Association of National Advertisers, Inc., 1979.

"Reese's Pieces sales blast off with E.T.," Marketing Communications,

September, 1982 . 


\section{SOURCES (CONT.)}

"The Role of Attitude Toward the Ad as a Mediator of Advertising Effectiveness: A Test of Competing Explanations," Journal of Marketing Research, Vol. 23, May 1986.

Ross, Harold L., "Recall Versus Persuasion: An Answer," Journal of Advertising Research, 22, 1982.

Rotkin, Nora J., "Product Visibility in Motion Pictures," Marketing Communications, Sept., 1982, (Advertisement.)

Schwartz, Joe, "Americans Go To The Movies," American Demographics, Sept., 1986.

Shorkey, Betsy, "Kovoloff's Casting Rockets to Stardom," ADWEEK, Feb. 18, 1985.

Spillman, Susan, "Marketers Race to Leave Their Brand on Films, Advertising Age, July 1, 1985.

"Staying Ahead of the Trends," The Hollywood Reporter, June 2, 1987.

Young, Jeff, V.P., Marketing, Unique Product Placements. 
APPENDIX 1/SUMMARY OF DATA PER MOVIE

Nightmare on Elmstreet

(Horror)

Gold Medal Maxwe11 House Diet Coke Marlboro Miller

$\begin{array}{lccccc}\text { Correct Recal1 } & 3 \% & 56 \% & 73 \% & 13 \% & 22 \% \\ \text { Incorrect Recal1 } & 3 \% & 24 \% & 13 \% & 8 \% & 11 \% \\ \text { Can Not Recal1 } & 94 \% & 21 \% & 14 \% & 79 \% & 66 \% \\ \text { Loya1 User } & 13 \% & 46 \% & 35 \% & 17 \% & 13 \% \\ \text { Frequent User } & 22 \% & 30 \% & 32 \% & 8 \% & 33 \% \\ \text { Rare User } & 25 \% & 8 \% & 6 \% & 6 \% & 21 \% \\ \text { Trial User } & 0 \% & 0 \% & 0 \% & 2 \% & 2 \% \\ \text { Non User } & 40 \% & 16 \% & 27 \% & 67 \% & 32 \% \\ \text { Type } & \text { Implied } & \text { Imp1ied } & \text { Implied } & \text { Imp } 11 \text { ied } & \text { Imp } 1 \text { ied } \\ \text { Time } & 0-3 \text { Sec } & 4-9 \text { Sec } & 4-9 \text { Sec } & 0-3 & 0-3\end{array}$

Average Rate- 3.84

Rate 1-5

$\begin{array}{cc}\text { Rate } & \text { Rate } 2 \\ 0 \% & 6 \%\end{array}$

Rate 3
$27 \%$

Rate 4

Rate 5

$43 \%$

$24 \%$

Male- $38 \%$

Female-62\%

Age 1-6
(1) $12-17$
$33 \%$
(2) $18-23$
$43 \%$
(3) $24-29$
$16 \%$

(4) $30-35$

(5) $36-41$
$3 \%$

(6) $42 \&$ up

$2 \%$

$3 \% \quad 3 \%$

* Rate was measured based on the respondent's liking of the movie on a scale of one to five. 


\section{APPENDIX $1 /$ CONT}

\section{Outrageous Fortune}

(Adult Comedy)

Coke Classic Colton Tobacco Sony TicTacs Quaker State

$\begin{array}{lccccc}\text { Correct Recal1 } & 25 \% & 21 \% & 4 \% & 72 \% & 8 \% \\ \text { Incorrect Recal1 } & 10 \% & 2 \% & 4 \% & 4 \% & 2 \% \\ \text { Can Not Recal1 } & 65 \% & 77 \% & 92 \% & 25 \% & 90 \% \\ \text { Loyal User } & 47 \% & 0 \% & 13 \% & 38 \% & 26 \% \\ \text { Frequent User } & 36 \% & 0 \% & 28 \% & 26 \% & 17 \% \\ \text { Rare User } & 8 \% & 0 \% & 8 \% & 15 \% & 23 \% \\ \text { Trial } & 0 \% & 0 \% & 8 \% & 0 \% & 8 \% \\ \text { Non User } & 9 \% & 100 \% & 43 \% & 21 \% & 8 \% \\ \text { Type } & \text { Implied } & \text { Integrated } & \text { Implied } & \text { Verbal } & \text { Creative } \\ \text { Time } & 4-9 \text { Sec } & 16-29 \text { Sec } & 0-3 \text { Sec } & 0-3 \text { Sec } & 4-9 \text { Sec }\end{array}$

Average Rate-3.66

Rate 1-5

Rate 1

$4 \%$
Rate 2
$4 \%$
Rate 3
$26 \%$

Rate 4

$55 \%$
Rate 5

$11 \%$
Male- $42 \%$

Age 1-6

\section{Female-58\%}

(3) $24-29$

$23 \%$
(4) $30-35$

$19 \%$
(5) $36-41$ $15 \%$
(6) $42 \&$ up $13 \%$ 


\section{Some Kind of Wonderful \\ (Teen Comedy)}

Valvoline TatorTots Marlboro Suzuki Jeep J\&J Baby Shampoo

$\begin{array}{lrrrrr}\text { Correct Recal1 } & 2 \% & 54 \% & 81 \% & 24 \% & 20 \% \\ \text { Incorrect Recal1 } & 4 \% & 0 \% & 4 \% & 6 \% & 4 \% \\ \text { Can Not Recal1 } & 94 \% & 46 \% & 15 \% & 70 \% & 76 \% \\ \text { Loyal User } & 6 \% & 9 \% & 7 \% & 0 \% & 24 \% \\ \text { Frequent User } & 9 \% & 35 \% & 9 \% & 2 \% & 41 \% \\ \text { Rare User } & 19 \% & 28 \% & 2 \% & 4 \% & 13 \% \\ \text { Trial User } & 4 \% & 2 \% & 2 \% & 2 \% & 2 \% \\ \text { Non User } & 63 \% & 26 \% & 78 \% & 92 \% & 20 \% \\ \text { Type } & \text { Implied } & \text { Verbal } & \text { Implied } & \text { Implied } & \text { Unassociated } \\ \text { Time } & 4-9 \text { Sec } & 0-3 \text { Sec } & 0-3 \text { Sec } & 0-3 \text { Sec } & 4-9 \text { Sec }\end{array}$

Average Rate- 4.3

$\begin{array}{cccccc}\text { Rate } 1-5 & \text { Rate } 1 & \text { Rate } 2 & \text { Rate } 3 & \text { Rate } 4 & \text { Rate } 5 \\ 0 \% & 40 \% & 26 \% & 44 \% & 26 \%\end{array}$

Male-24\% Female-76\%
Age 1-6
(1) $12-17$
(2) $19-23$
(3) $24-29$
(4) $30-35$ $33 \%$
$22 \%$
$7 \%$
$13 \%$
(5) $36-41$
$4 \%$
(6) $42 \&$ up
$9 \%$ 


\section{APPENDIX $1 /$ CONT.}

\section{Lethal Weapon}

(Adult Action)

\section{Winston Coors Quaker Oats Alka Seltzer Canadian Mist}

$\begin{array}{lccccc}\text { Correct Recal1 } & 13 \% & 36 \% & 3 \% & 63 \% & 15 \% \\ \text { Incorrect Recal1 } & 27 \% & 19 \% & 6 \% & 2 \% & 3 \% \\ \text { Can Not Recal1 } & 58 \% & 45 \% & 97 \% & 35 \% & 82 \% \\ \text { Loyal User } & 3 \% & 5 \% & 13 \% & 9 \% & 5 \% \\ \text { Frequent User } & 2 \% & 8 \% & 28 \% & 32 \% & 3 \% \\ \text { Rare User } & 2 \% & 26 \% & 19 \% & 15 \% & 60 \% \\ \text { Trial User } & 0 \% & 2 \% & 0 \% & 0 \% & 3 \% \\ \text { Non User } & 94 \% & 59 \% & 41 \% & 43 \% & 83 \% \\ \text { Type } & \text { Implied Implied } & \text { Unassoc. } & \text { Integrated } & \text { Verbal } \\ \text { Time } & 4-9 & 30 \text { \& up } & 0-3 & 10-15 \text { Sec } & 0-3\end{array}$

Average Rate- 4.3

Rate 1-5
Rate 1 Rate 2
$0 \%$
$0 \%$
Rate 3
$11 \%$

Rate 4
$48 \%$

Rate 5

$41 \%$

Male- $49 \% \quad$ Female- $51 \%$
Age 1-6-
(1) $12-17$
(2) $18-23$
(3) $24-29$
(4) $30-35$
(5) $36-41$
(6) $42 \&$ up
$20 \%$
$20 \%$
$5 \%$
$9 \%$ 


\section{APPENDIX $1 /$ CONT. \\ Raising Arizona \\ (Adult Comedy)}

Christian Dior Kelloggs Lays Dunkin Donuts Huggies

$\begin{array}{lccccc}\text { Correct Recal1 } & 50 \% & 64 \% & 0 \% & 77 \% & 93 \% \\ \text { Incorrect Recal1 } & 5 \% & 7 \% & 2 \% & 0 \% & 5 \% \\ \text { Can Not Recal1 } & 45 \% & 30 \% & 98 \% & 23 \% & 16 \% \\ \text { Loyal User } & 16 \% & 20 \% & 16 \% & 0 \% & 0 \% \\ \text { Frequent User } & 7 \% & 48 \% & 43 \% & 14 \% & 2 \% \\ \text { Rare User } & 11 \% & 23 \% & 36 \% & 73 \% & 0 \% \\ \text { Trial User } & 5 \% & 0 \% & 2 \% & 11 \% & 82 \% \\ \text { Non User } & 61 \% & 9 \% & 2 \% & \text { Verbal } & \text { Integrated } \\ \text { Type } & \text { Verbal } & \text { Implied } & \text { Unassoc. } & 0-3 & 30 \\ \text { Time Sec } & 4-9 \text { Sec } & 10-15 & \text { Sec }\end{array}$

Average Rate- 2.52

Rate 1-5-

Rate 1

Rate 2 Rate 3

Rate 4

Rate 5

$20 \%$

$27 \%$

$32 \%$

$20 \%$

$0 \%$

Male-45\%

Female-55\%

Age 1-6

(1) $12-17$

(2) $18-23$

(3) $24-29$

(4) $30-35$

(5) $36-41$

(6) $42 \&$ up

$11 \%$

$27 \%$

$14 \%$

$16 \%$

$11 \%$ 
APPENDIX 1/ CONT .

Project $X$

(Teen Drama)

\title{
Twinkies
}

Sun Maid

Budweiser

Pepsi

Winston

Correct Reca11

$72 \%$

$84 \%$

$36 \%$

$8 \%$

$40 \%$

Incorrect Recall

$0 \%$

$0 \%$

$12 \%$

$4 \%$

$20 \%$

Can Not Recal1

$28 \%$

$16 \%$

$52 \%$

$88 \%$

$40 \%$

Loyal User

$60 \%$

$36 \%$

$16 \%$

$60 \%$

$8 \%$

Frequent User

$16 \%$

$20 \%$

$28 \%$

$32 \%$

$0 \%$

Rare user

$12 \%$

$28 \%$

$12 \%$

$8 \%$

$0 \%$

Trial User

$0 \%$

$0 \%$

$0 \%$

$0 \%$

$0 \%$

Non User

$12 \%$

$16 \%$

$44 \%$

$0 \%$

$92 \%$

Type

Implied

Implied

Implied

Implied

Implied

Time

4-9 Sec 0-3 Sec

4-9 Sec

0-3 Sec

4-9 Sec

Average Rate- 4.12

Rate 1-5

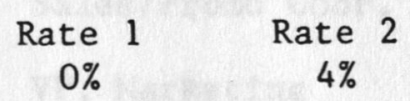

Rate 3
$16 \%$

Rate 4

$44 \%$

Rate 5

$36 \%$

\begin{abstract}
Kale- $52 \%$
Female-48\%
\end{abstract}

Age 1-6

(1) $12-17$

(2) $18-23$

$52 \%$

(3) $24-29$

(4) $30-35$

$12 \%$

(5) $36-41$

$16 \%$

(6) $42 \underset{0 \%}{\text { up }}$ 


\section{APPENDIX 2}

\section{Professional Interviews}

Name

Gerald Bagg

Jeffrey C. Young

Judith Goodman

Steven Halpern

Michael Harpster

Jeff Coleman

James Roosa

William Brown

Steve Fountaine

George Ker

Thomas Hurley

Alice M. Gereaux

Robert Blanchard

Steve Matis

Melvin J. Grayson

Mari $D^{-}$Alessandro

Doug Christoph
Title/Department

Account Exec

Marketing Director

Asst . to CEO

Dir. Production Res. Touchstone Pictures

Distribution

Feature Productions

Advertising Research

Media Director

VP, Mktg. Research

VP, Advertising

Brand Manager

Sales/Promo Coor.

VP, Marketing

VP, Mktg. Research

VP, Corp. Affairs

Assoc. Mgr. Creative

Spvs. Movie Plcmnt.
Corporation or Agency

Associated Film Promotions

Unique Product Placment

DeLaurentiis Entertainment Group

New Line Cinemas

Paramount Pictures

J. Walter Thompson

Quaker Oats Corporation

Kimberly-Clark Corporation

Kimberly-Clark Corporation

Ralston Purina Corporation

Anheuser Busch, Inc.

Colgate-Palmolive Corporation

Colgate-Palmolive Corporation

Nabisco Brands, Inc.

General Mills, Inc.

Miller Brewing Co. 


\section{APPENDIX 3/ SAKPLE QUESTIONS}

Nightmare on Elmstreet III/Dream Warriors

How many times have you seen Nightmare on Elmstreet III including last night?

$$
\begin{array}{lllllll}
0 & 1 & 2 & 3 & 4 & 5 & 6 \text { (more) }
\end{array}
$$

How would you rate that movie on a scale from one to five, with five being the best?

Do you recall seeing any brand name products, signs or clothing appearing in the movie? 1-Yes 2-No If yes, which brands do you remember?

1-Gold Medal Flour 2-Elmer's Glue 3-WestClox 4-Diet Coke

5-Maxwell House Coffee 6-Aunt Jemima 7-Coca-Cola 8-Little Nemos

9-Budweiser 10-Miller Beer 11-Marlboro Cigarettes

12-Lite

13-Nissan

Perhaps with some assistance you can remember the brands featured.

What brand of flour did the blonde dream warrior use in the opening scenes to build the house in her dreams?

1-Correct Brand Recall

2-Incorrect Brand Recall

3-Can Not Reca11

What brand of coffee did she eat to stay awake?

1-Correct Brand Recall 2-Incorrect Brand Recall

3-Can Not Recall

What brand of soft drink did she wash the coffee down with?

1-Correct Brand Recall 2-Incorrect Brand Recall

3-Can Not Recall

What brand of cigarettes was lying on the table when the two psychologists went to the bar to confront the father who knew where Freddie's bones were? 1-Correct Brand Recall 2-Incorrect Brand Recall 3-Can Not Recall

What brand of beer was the father drinking?

1-Correct Brand Recal1

2-Incorrect Brand Recal1

3-Can Not Recall

Please classify yourself as either a loyal user(always buy), frequent user(usually buy), rare user(buy on occasion), trial user (have tried once), non-user(never used) when I mention the following brand names.

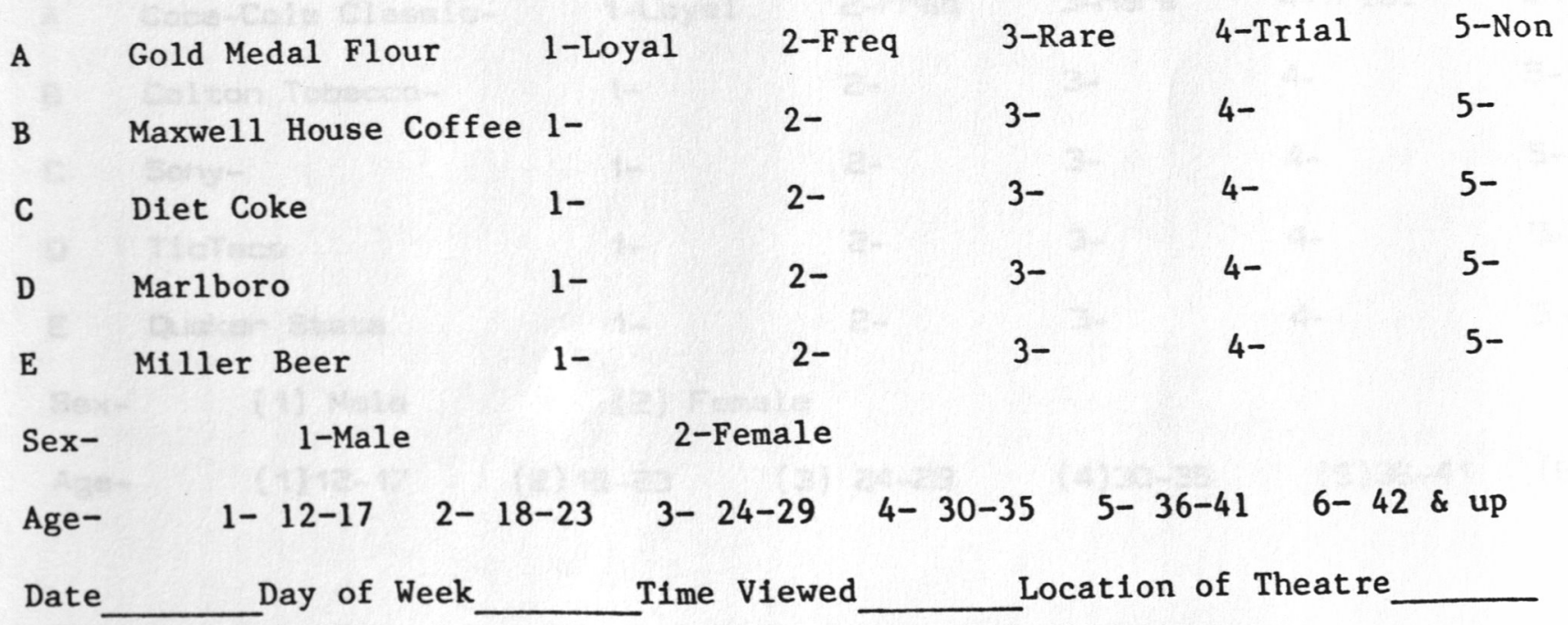


How many times have you seen Outrageous Fortune including last night?
0
1
2
3
4
6 (more)

Do you recall seeing any brand name products, signs or clothing appearing in Outrageous Fortune? 1-Yes 2-No

If yes, which brand names do you remember?

1-Classic Coca-Cola 2-Nike 3-Sony Video Camera 4-Colton's Tobacco

5-Gatorade 6-Minute-Maid 7-Eastern Airlines 8-TicTacs

9-Quaker State 10-Maxwell House Coffee 11-Chef-Boy-Ardee 12-Ford Van

13-VanCamps Pork \& Beans 14-Coors 15-Burger King

Incorrect Brand Neme Recall:

Perhaps with some assistance you will recall some of the brands featured.

What brand of soft drink did Shelly Long's character get from a manchine after ballet practice in the opening scene? 1-Correct Brand Recall 2-Incorrect Brand Recall 3-Can Not Recall

What brand of tobacco did the actresses' boyfrienc! exclusively buy throughout the film? 1-Correct Brand Recall 2-Incorrect Brand Recall 3-Can Not Recall

What brand of video camera did Shelly Long talk to her parents through when asking for money? 1-Correct Brand Recall

2-Incorrect Brand Rec 3-Can Not Recall

What brand of breath mint did Shelly Long offer Bette Midler when they finally tracked down the boyfriend they shared? 2-Incorrect Brand Recall 3-Can Not Recall

What brand of oil was featured on a sign in the old boat house where the man hid? 1-Correct Brand Recall 2-Incorrect Brand Recall

3-Can Not Recall

Now I would like you to classify yourself as a loyal user ( 1 iweys buy), frequent user(usually buy), rare user (on occasion buy), trial user (have tried once), or a non-user (have never used).

$\begin{array}{lllllll}\text { A Coca-Cola Classic- } & 1 \text {-Loyal } & \text { 2-Freq } & 3-\text { Rare } & 4-\text { Trial } & \text { 5-Non } \\ \text { B Colton Tobacco- } & 1- & 2- & 3- & 4- & 5- \\ \text { C Sony- } & 1- & 2- & 3- & 4- & 5- \\ \text { D TicTacs } & 1- & 2- & 3- & 4- & 5- \\ \text { E } & \text { Quaker State } & 1- & 2- & 3- & 4- & 5-\end{array}$
Sex-
(1) Male
(2) Female

Age- (1) $12-17$

(2) $18-23$

(3) $24-29$

(4) $30-35$

(5) $36-41$

(5) 42 
many times have you seen Some kind of Wonderful including last night? $\begin{array}{lllllll}0 & 1 & 2 & 3 & 4 & 5 & 6 \text { (more) }\end{array}$

would you rate it on a scale from one to five with five being the best? $\begin{array}{llllll}0 & 1 & 2 & 3 & 4 & 5\end{array}$

you recall seeing any brand name products, signs or clothing appeariny

in some Kind of Wonderful? 1-Yes 2-No

yes, which brands do you remember?

lalvoline 2-Garbage Pail Kids 3-Levi Jeans 4-oreIda Tator Tots cookies? 6-Marlboro Cigarettes 7-Liquor? 8-Mercedez Benz ford 10-Smuckers 11-ketchup 12-Chapstick 13-suzuki Jcep Pepsi Cups 15-Johnson \& Johnson Shampoo correct Brand Recall:

haps with some assistance, you can recall some of the brands featured.

t brand of oil was shown in the garage while the star worked on a car? 1-Correct Brand Recall 2-Incorrect Brand Recall 3-Can Not Recall

ft frozen potato product did the sister call her brother at breakfast? 1-Correct Brand Recall 2-Incorrect Brand Recall 3-Can Not Recall

t brand of cigarettes did the principal take from the punk student? 1-Correct Brand Recall 2-Incorrect Brand Recall 3-Can Not Recall

t model car did the rich girl give the star a ride home in? 1-Correct Brand Recall 2-Incorrect Brand Recall 3-Can Not Recall

t brand of shampoo was shown in the shower while the star prepared for date?

1-Correct Brand Recall 2-Incorrect Brand Recall 3-Can Not Recall

fase classify yourself as a loyal user(always buy,) frequent user(usually buy, ) rare user(buy on occasion,) trial user(tried once, ) or a nonuser(have never used) for the following products.

$\begin{array}{llllll}\text { Valvoline } & 1 \text {-Loyal } & 2 \text {-Freq } & 3 \text {-Rare } & 4-\text { Trial } & 5-N o n \\ \text { Tator Tots } & 1- & 2- & 3- & 4- & 5- \\ \text { Marlboro } & 1- & 2- & 3- & 4- & 5- \\ \text { Suzuki Jeep } & 1- & 2- & 3- & 4- & 5- \\ \text { Johnson Baby } & 1- & 2- & 3- & 4- & 5-\end{array}$
(1) Male
(2) Female
(1) $12-17$
(2) 18-23
( 3 ) $24-29$
(4) $30-35$
(5) $36-41$
(6) 42-up 
many times have you seen Lethal Weapon including last night(yesterday)?

$$
\begin{array}{lllllll}
0 & 1 & 2 & 3 & 4 & 5 & 6 \text { (more) }
\end{array}
$$

would you rate that movie on a scale of 1 to 5 , with 5 being the best?

$$
\begin{array}{llllll}
0 & 1 & 2 & 3 & 4 & 5
\end{array}
$$

you recall seeing any brand name products, signs or clothing appearing in the movie? 1-Yes 2-No If yes, which brands do you remember?

Ainston 2-Folgers Instant Coffee 3-NorthCold 4-Coors Beer 5-Quaker 0ats Gold Medal Flour 7-Dove Dish Washing Liquid 8-Pepto Bismal 9-DelMonte Juice DelMonte Vegetables 11-MeisterBrau 12-Alka Seltzer 13-Smith \& Wesson Berretta 15-Pepsi 16-Pierrer Water 17-Honda Scooter 18-Ploneer $\begin{array}{llccc}\text { Canadian Mist } & \text { 20-Heinze Ketchup 21-Shamrock 22-Mitsubishi } & \text { 23-GoBots } \\ \text { - Party Egg Nog } & \text { 25-Shampoo(Clairol) } & \text { 26-Dessert(Tarts-SaraLee?) 27-MasterCard }\end{array}$ -Visa 29-Mobira Radio Unit 30-Milk Truck(Rockren) 31-Federal Express Truck

thaps with some assistance, you can remeber the brands featured.

t brand of cigarettes did Mel Gibson smoke throughout the movie; the pack was shown lying beside him inside his camper and he took the pack out after the explosion at the prosititue's house?

1-Correct Brand Recall 2-Incorrect Brand Recall 3-Can Not Recall

at brand of beer did the two stars drink while hanging out on the boat after dinner? Mel was shown drinking this brand when he first woke up and Danny drank it at night? 1-Correct Brand Recall 2-Incorrect Brand Recall 3-Can Not Recall

brand of instant breadfast cereal was shown in Danny Glover(Murtaugh's) kitchen cabinet when he got a glass for his DelMonte julce. This was after his cake in the bathtub.

1-Correct Brand Recall 2-Incorrect Brand Recall 3-Can Not Recall

at brand of anti-acid was shown advertised on a large screen Pioneer TV set while the two guys watched part of a football game?

1-Correct Brand Recall 2-Incorrect Brand Recall 3-Can Not Recall

at brand of liquor did Murtaugh offer Riggs before they sat down to dinner. This was the first time Riggs had met his family and the daughter filrted with him. 1-Correct Brand Recall 2-Incorrect Brand Recall 3-Can Not Recall

en I mention the following brand names, please classify yourself as a loyal buyer(always buy), frequent buyer(usually buy), rare buyer(buy on occasion), trial user(have bought once), or non-user(have never bought).

$\begin{array}{llllll}\text { Winston } & \text { 1-Loyal } & \text { 2-Freq } & \text { 3-Rare } & \text { 4-Trial } & \text { 5-Non } \\ \text { Coors } & \text { 1-Loyal } & \text { 2-Freq } & \text { 3-Rare } & \text { 4-Trial } & \text { 5-Non } \\ \text { Quaker Oats } & \text { 1-Loyal } & \text { 2-Freq } & \text { 3-Rare } & \text { 4-Trial } & \text { 5-Non } \\ \text { Alka Seltzer } & \text { 1-Loyal } & \text { 2-Freq } & \text { 3-Rare } & \text { 4-Trial } & \text { 5-Non } \\ \text { Canadian Mist } & \text { 1-Loyal } & \text { 2-Freq } & \text { 3-Rare } & \text { 4-Trial } & \text { 5-Non }\end{array}$
(1) Male
(2) Female

(1) $12-17$

(2) $18-23$

(3) 24-29

(4) $30-35$

(5) $36-41$

(6) $42 \&$ Up 
How many times have you seen Raising Arizona including yesterday?

$$
\begin{array}{lllllll}
0 & 1 & 2 & 3 & 5 & & \\
6 \text { (more) }
\end{array}
$$

How would you rate that movie on a scale of 1 to 5 with 5 being the best? Do you recall seeing any brand name products or merchandise appearing in the movie? 1-Yes 2-No If yes, which brands?

1-Radio Shack 2-Christian Dior 3-Huggies 4-Gerbers 5-Nikon 6-M\&M's 7-Royal Crown hair grease 8-Almost Home Cookies 9-Coke 10-Kellogg's Corn Flakes 11-Frito Lay Products--Doritos, Lays chips 12-Oreos 13-Dove 15-Snuggles 16-Chips Ahoy 17-Twinkies 18-Hostess Cupcakes 19-Johnson Baby products 20-Pepsi 21-Brawny Paper Towels 22-Luvs 23-Pampers 24-Quaker Oats 25-Dunkin Donuts 26-Signal 27-Gator

Perhaps with some assistance you can remember more brands featured.

When Nathan Arizona and his wife were relaxing in their living room, what clothes designer did Nathan show his wife in the newspaper and ask if people really pay money for this stuff?

1-Correct Brand Recall 2-Incorrect Brand Recall 3-Can Not Recall

What brand of cereal did HI and his convict friends eat for breakfast? 1-Correct Brand Recall 2-Incorrect Brand Recall 3-Can Not Recall

What brand of potato chipswere sitting on the couch with the convicts while they drank Budweiser and told HI about their bank robbing plans? 1-Correct Brand Recall 2-Incorrect Brand Recall 3-Can Not Recall

When the Harley biker went to see Nathan Arizona he said "when you want to find a convict you hire a convict, when you want to find a What, the police ..." where did he suggest the police hang out?

1-Correct Brand Recall 2-Incorrect Brand Recall 3-Can Not Recall

What brand of disposable diapers did HI choose to rob from the convenien store?

1-Correct Brand Recall 2-Incorrect Brand Recall 3-Can Not Recall

When I mention the following brand names please tell me if you or someone in your family is a loyal buyer(always buy,) frequent buyer (usually buy,) rare buyer(buy on occasion,) trial buyer(have bought once,) or a non-buyer (have never bought.)

1-Christian Dior 1-Loyal 2-Freq 3-Rare 4-Trial 5-Non

2-Kellogg's Corn Flakes

3-Lays Potato Chips 1-Loyal 2-Freq 3-Rare 4-Trial 5-Non

4-Dunkin Donuts 1-Loyal 2-Freq 3-Rare 4-Trial 5-Non

5-Huggies 1-Loyal 2-Freq 3-Rare 4-Trial 5-Non

Sex- (1) Male (2) Female

Age-

(1) $12-17$

$\begin{array}{ll}\text { (2) } 18-23 & \text { (3) } 24-29\end{array}$

(4) $30-35$

(5) $36-41$

(6) $42 \&$ 


\section{Project $\mathrm{X}$}

How many times have you seen Project $\mathrm{X}$ including yesterday?

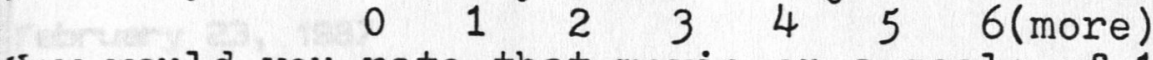

How would you rate that movie on a scale of 1 to 5 , with 5 being the bes $\begin{array}{llllll}0 & 1 & 2 & 3 & 4 & 5\end{array}$

Do you recall seeing any brand name products or merchandise appearing in the movie 1-Yes 2-No If yes, which brands do you recall? 1-Mark-A-Lot 2-Reebok 3-Twinkies 4-Sun Mald Raisins 5-Budweiser 6-Bud Light 7-Michelob 7-Winston 8-0ld Spice 9-Joy 10-Pepsi 11-Wizard 12-M\&Ms

Perhaps with some assistance you will recall more brands featured.

What. brand of snack cake did Garrett offer Virgil the monkey after he completed his flight training?

1-Correct Brand Recall 2-Incorrect Brand Recall 3-Can Not Recall

What brand of raisins did the monkeys get for rewards.

1-Correct Brand Recall 2-Incorrect Brand Recall 3-Can Not Recall

What brand of beer did Garrett drink while he was watching t.v. and discovered about the sign language? He also drank this brand while in the bar playing cards with the guys.

1-Correct Brand Recall 2-Incorrect Brand Recall 3-Can Not Recall

What brand of cola were the watchmen drinking before the monkeys broke out of the research center?

1-Correct Brand Recall 2-Incorrect Brand Recall 3-Can Not Recall

What brand of cigarettes did Garrett smoke? He used them to bribe Golic 1-Correct Brand Recall 2-Incorrect Brand Recall 3-Can Not Recall

When I mention the following brand names please tell me if you or someone in your family is a loyal buyer(always buys,) frequent buyer (usually buys,) rare buyer(buy on occasion,) trial buyer(have bought once,) or a non-buyer( have never bought.)

$\begin{array}{llllll}\text { 1-Twinkies } & \text { 1-Loyal } & \text { 2-Freq } & \text { 3-Rare } & \text { 4-Trial } & \text { 5-Non } \\ \text { 2-Sun Maid } & \text { 1-Loyal } & \text { 2-Freq } & \text { 3-Rare } & \text { 4-Trial } & \text { 5-Non } \\ \text { 3-Eudweiser } & \text { 1-Loyal } & \text { 2-Freq } & \text { 3-Rare } & \text { 4-Trial } & \text { 5-Non } \\ \text { 4-Pepsi } & \text { 1-Loyal } & \text { 2-Freq } & \text { 3-Rare } & \text { 4-Trial } & \text { 5-Non } \\ \text { 5-Winston } & \text { 1-Loyal } & \text { 2-Freq } & \text { 3-Rare } & \text { 4-Trial } & \text { 5-Non }\end{array}$

Sex-

Age-

(1) Male

(1) $12-17$

(2) $18-23$

(2) Female

Date Day of Week (3) $24-29$

(4) $30-35$

(5) $36-41$

(6) $42 \&$ Time Viewed Location of theat 
February 23, 1987

Charles E. Decker

vice President

Advertising

Quaker Oats Company

Merchandise Mart Plaza

Chicago Illinois 60654

Dear Mr. Decker:

I'm currently working on my masters degree in Mass Communications and my thesis concerns the placement of brand name products within motion pictures. Attached is a very general outline of my researchi objectives.

I'm writing to you since Quaker Dats has had some recent Film debuts. I think my Favorite was Ken-L Fation in 'Back To The Future.' As an advertising graduate student, I became interested in product placement as a technique to gain brand name exposure. It seemed too good to be true. You could reach a large audience of captlve viewers in a non-commercial environment at a low cost-per-thousand. But, what happens if the brand name that's featured doesn't register with the consumer? I have always been critical of using projected audience size alone to measure communication effectiveness. I believe the most significant aspect of my thesis will be the generation of reliable brand name recall scores for a varlety of product placements.

I'm very anxious to hear your opinions concerning the effectiveness of product placement. I would like to include the Quaker Oats Company perspective in my thesis. However, if you prefer I will keep any information you share with me anonymous.

I feel confident that my research will generate a wealth of useful qualitative and quantitative data. If you are interested, I will share my research results with you when my thesis is complete.

I hope to hear from you or a brand manager from Quaker Oats soon. I would value any suggestions you had to offer which would make my research more valuable to manufacturers.

Best wishes for a prosperous year at Quaker Oats Company!

Very truly yours,

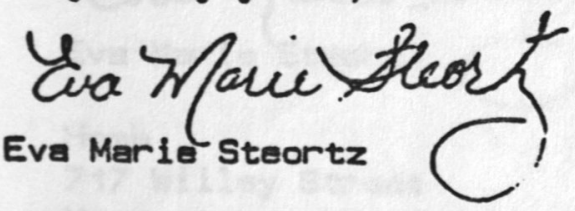

Home

717 Willey Street

Morgantown, WV 26505

(304) 296-1916

\section{Office}

Institurional Advancement West Virginia University Morgantown, WV 26506 
February 23, 1987

Margaret S. Busch

Vice President

Corporate Fromotions

Anheuser-Busch Company

One Busch Place

St. Louis, Missour 1 63118

Dear Ms. Busch:

I'm currently working on my masters degree in Mass Communications and my thesis concerns the placement of brand name products within motion pictures. Attached is a very general outline of my research objectives.

I'm writing to you because in my opinion Budweiser deserves an Oscar far its appearances in so many recent box office hits. In 'Top Gun' one would believe long neck bottles of Bud were all the bar served.

As an advertising graduate, I always considered product placement an excellent technique to gain brand name exposure. You could reach a large audience of captive viewers in a non-commercial enviromment at a low cost-per-thousand. But, what if the brand name featured doesn't register with the consumer. The most significant aspect of my thesis will be the generation of reliable brand name recall scores. I have always been critical of using audience measurement alone to indicate communication effectiveness.

I'm very anxious to hear your opinions concerning product placement in motion pictures. I would like to include the Anheuser-Busch Company perspective in my thesis. However, if you prefer I will keep any information you share with me anonymous.

I Feel confident that my research will generate a wealth of useful qualitative and quantitative data. If you are interested, I will share my research results with you when my thesis is complete.

I hope to hear from you or a brand manager from Anaheuser-Busch soon. I will value any suggestions you have to offer..

Best wishes for keeping Budweiser the king of beer!

Very truly yours,

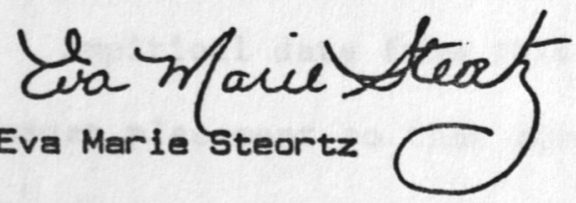

Home

717 Willey Street

Morgantown, WV

(304) 296-1916

\section{Office}

Institutional Advancement West Virginia University Morgantown, WV 26505 


\section{ABSTRACT}

This thesis is the first known research involving brand name exposure within motion pictures. The project generated informed insight and reliable quantified data concerning the effectiveness of product placement. Thus, this thesis provides a valuable source for manufacturers contemplating the implications of gaining brand name exposure for their products or services via the motion picture medium.

A background and description of product placement are provided based on a literature search and interviews with professionals. Product placement is deemed cost efficient based on comparisons with television commercials and theatre sponsored trailers.

The communication effects of product placement were analyzed based on day-after brand name recall scores generated from natural theatre settings. Thirty placements were chosen for analysis. Correct brand name recall ranged from 0 to 93 percent. The average correct recall was 38 percent. Therefore, it is suggested that brand name exposure within motion pictures does provide effective communication. Cross-tabulations between recall and the following variables -- 11king of the movies, integration into the movies, seconds of exposure, product usage, age and sex-- provided tables and chisquare statistics which indicated each variable resulted in significant differences in recall.

Empirical data from this study can be used during the planning stages of product placement so that more effective use can be made of this advertising alternative. Manufacturers may also use this information to predict the impact of their brand name exposure upon movie viewers. 
EVA MARIE STEORTZ

Route 2, Box 389

Sistersville, WV 26175

(304) 652-2594

EDUCATION

$\begin{array}{ll}\text { M.S.J. } & \text { Mass Communications } \\ \text { Minor Field: } & \text { Business Administration } \\ \text { Thesis: } & \text { The Communication Effects and Cost Efficiency } \\ & \text { Associated With Brand Name Exposure Within } \\ & \text { Motion P1ctures, West Virginia University, } \\ & \text { September 1987 } \\ \text { Honors: } & \text { Student Teaching Assistantship } \\ \text { B.S.J. } & \text { Major: Journalism/Advertising (Emphasis on } \\ & \text { Minors: Marketing \& Psychology } \\ \text { Honors \& Activities: } & \text { Dest Virginia University, May 1985 } \\ & \text { Ameans List } \\ & \text { Amp Student Competition (1985, Burger King) } \\ & \text { American Marketing Association } \\ & \text { Film Committee }\end{array}$

EXPERIENCE :

Administrative Staff Assistant

Advertising Lab Instructor

Chemical Plant Pipe Insulator

Reta11 Sales Person

Hobbies \& Interests
(May 1986-present) Institutional

Advancement, West Virginia University. Coordinated and promoted special events sponsored by WVU. Also responsible for the inventory and audit of public relations publications generated throughout the university.

(August 1985-present) WVU School of Journalism. Developed $1 \mathrm{ab}$ exercises based on real advertisers, objectives and target markets. Discussed concepts such as unique sales benefit, market segmentation and psychographics. Introduced students to general layout and format mechanics for each medium.

(May 1984-August 1984) Union Carbide Corporation, Sistersville, WV. Responsible for insulating and water-proofing tanks and pipe trails throughout plant.

(Summers 1982-1983) Custom Tees \& Tops, Sistersville, WV. Responsibilities included inventory control, pricing, opening register, tallying recelpts, as well as encouraging customer transactions. Socializing, observing people, watching movies, reading magazines and collecting pig-related items. 
APPROVAL OF EXAMINING COMMITTEE

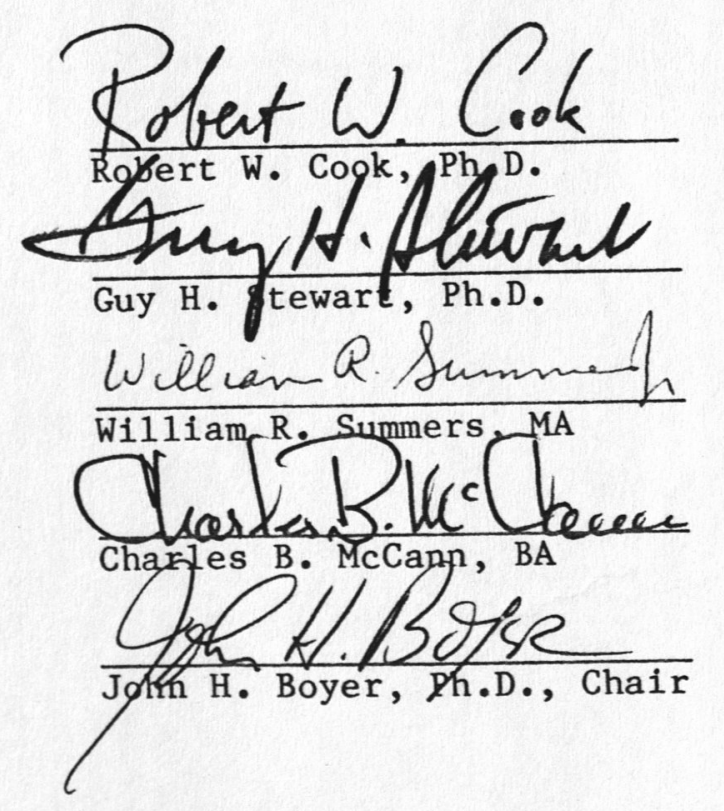

